
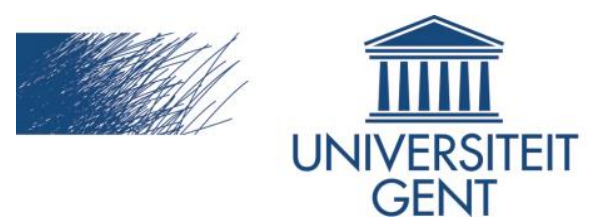

biblio.ugent.be

The UGent Institutional Repository is the electronic archiving and dissemination platform for all UGent research publications. Ghent University has implemented a mandate stipulating that all academic publications of UGent researchers should be deposited and archived in this repository. Except for items where current copyright restrictions apply, these papers are available in Open Access.

This item is the archived peer-reviewed author-version of: Nanomaterials to avoid and destroy protein aggregates

Authors: Sauvage F., Schymkowitz J., Rousseau F., Schmidt B.Z., Remaut K., Braeckmans K., De Smedt S.C.

In: Nano Today, 31, Article Number: 100837

To refer to or to cite this work, please use the citation to the published version:

Sauvage F., Schymkowitz J., Rousseau F., Schmidt B.Z., Remaut K., Braeckmans K., De Smedt S.C. (2020) Nanomaterials to avoid and destroy protein aggregates

Nano Today, 31, Article Number: 100837

DOI: 10.1016/j.nantod.2019.100837 


\title{
Nanomaterials to avoid and destroy protein aggregates
}

\author{
Félix Sauvage ${ }^{1}$, Joost Schymkowitz ${ }^{2,3}$, Frederic Rousseau ${ }^{2,3}$, Bela Z. Schmidt ${ }^{2,3}$, Katrien \\ Remaut $^{1}$, Kevin Braeckmans ${ }^{1}$ and Stefaan C. De Smedt ${ }^{1 *}$
}

\begin{abstract}
${ }^{1}$ Lab. General Biochemistry \& Physical Pharmacy, Faculty of Pharmaceutical Sciences, Ghent University, Ottergemsesteenweg 460, Ghent, Belgium
\end{abstract}

${ }^{2}$ Switch Laboratory, VIB, B-3000 Leuven, Belgium.

${ }^{3}$ Dept. of Cellular and Molecular Medicine, KU Leuven, B-3000, Leuven, Belgium

*Corresponding author: Stefaan.desmedt@ugent.be

\begin{abstract}
Aggregation of proteins is involved in many disorders. Besides amyloid fibrils, which mostly form in the brain, other kind of protein aggregates can lead, for example, to clots in the blood or floaters in the vitreous of the eye. This review is not only limited to amyloid diseases but aims at giving the reader a general overview on how nanomaterials can be employed to avoid and destroy protein aggregates of different nature. Thanks to their recognized versatility, nanomaterials may offer attractive features against harmful protein aggregates. In addition to their known ability to interact with proteins, we also aim at providing a state-of-the-art on how stimuli-responsive nanomaterials can be employed to destroy aggregates. Despite promising and conceptually interesting strategies on how nanomaterials can lead to the destruction of protein aggregates and the prevention of their formation, it appears clearly that many efforts still remain, however, to demonstrate in vivo feasibility and safety to pave the way for clinically relevant therapies.
\end{abstract}

Keywords Nanoparticles, amyloid, fibrillation, floaters, collagen, clots, synuclein 


\section{Introduction}

Proteins are of crucial importance for the functioning of cells and organisms. They play a fundamental role in physiological processes and have a structural function in tissues. In some situations, the accumulation of misfolded proteins leads to insoluble and highly stable toxic aggregates, called amyloid fibrils. Currently 36 human amyloid proteins are known [1]. The aggregation of such amyloidogenic peptides is involved in many neurodegenerative disorders such as Parkinson ( $\alpha$-synuclein aggregates), Alzheimer ( $\beta$-amyloid plaques), Huntington (polyglutamine aggregates) and Creutzfeldt-Jacob (amyloid deposits of the prion protein ( $P r P)$ ). Aggregation of amyloidogenic peptides can also be found in type-II diabetes and cataracts [25]. Besides amyloidogenic peptides, also other types of proteins can form aggregates according to various processes and induce different pathologies. For instance, the formation of thrombi, by a dysregulation of the hemostasis, also involves protein aggregation via polymerization of fibrin, thereby forming a network with aggregated platelets and coagulation factors [6]. Accumulation of proteins can also lead to more benign diseases. As an example, upon aging so named 'floaters' may occur in the vitreous due to the formation of collagen aggregates that cast shadows on the retina lowering visual acuity and contrast sensitivity [7]. Albeit not entirely constituted of proteins, kidney stones also involve proteins forming amalgams with organic or inorganic compounds [8]. All these types of aggregates might have a detrimental effect on human health and wellbeing. While extensive research is currently being carried out to get a better understanding of the pathophysiology of these diseases, many efforts still remain to be made to bring new therapeutic strategies. In addition to pharmacology and biology, the field of materials and, more particularly, nanomaterials may provide new avenues and original therapeutic approaches. 
During the last decades, nano-sized materials have been extensively studied by the drug delivery community and pharmaceutical companies to improve the administration of drugs and biologics (especially for cancer therapy); examples include the commercialization of Doxil@ (liposomal doxorubicin $\mathrm{HCl}$ ) and Ambisome (C) (liposomal Amphotericin B) in the 90s and, more recently, Onpattro® (lipid nanoparticles carrying siRNA). Also for clinical diagnosis nano-sized materials are attractive, as for instance superparamagnetic iron oxide nanoparticles which are used as contrast agents for magnetic resonance imaging (MRI), in particular for cancer [9]. The combination of diagnosis and drug delivery has led to the emergence of a new field called 'theranostics' where nano-sized materials play a central role as well [10].

Extensive efforts in chemistry and physics have led to better understanding of the physicochemical properties of nano-sized materials which might further open the field for new biomedical applications. Due to their large surface and versatile properties (size, shape, surface), nano-sized materials may be very well suited as well for optimal recognition and interaction with peptide/protein aggregates. Polymeric, lipid-based or inorganic nanoparticles could be surface-functionalized with different ligands (antibodies, aptamers, small molecules...), which might improve their interaction with specific amino-acid sequences, thus inhibiting aggregation. This review will not focus on the pharmacological treatment of diseases related to protein aggregates, but aims to shed light on the reported potential of 'drug free' nanomaterials in the management of protein aggregates through three strategic approaches, namely (i) preventing aggregate formation, (ii) clearing and (iii) destroying aggregates.

\section{Preventing the formation of peptide and protein aggregates with nanomaterials}

A main mechanism for protein aggregation, often described as 'fibrillation', is the conversion of soluble monomers into large insoluble linear aggregates (also called amyloids). The 
accumulation of such structures induces a loss of the protein function and high toxicity by disturbing intracellular transport, cellular functions and associated pathways. The formation of protein fibrils is a time-dependent process characterized by a sigmoidal curve consisting of a lag phase, an elongation phase and a final plateau regime [11]. As Figure 1A shows, the lag phase can be considered as a necessary 'waiting phase' or 'activation time' to activate nuclei and during which aggregation is not yet detectable. During this lag phase native protein monomers unfold. During the elongation phase monomers form oligomers that are elongating into beta-strand-stacked structures like protofibrils and/or fibrils until an equilibrium is reached (final plateau regime). It has been shown in vitro that the fibril formation occurs when the amount of monomers exceeds a 'critical aggregation concentration' following a mechanism very similar to the self-assembly of surfactants [12]. Many well-established methods can be employed to assess the fibrillation process. Several dyes like Thioflavin T (TfT) are commonly used because of their specific binding to cross- $\beta$-sheets structures resulting in enhanced fluorescence [13]. Other complementary techniques to study fibrillation are transmission electronic microscopy (TEM) imaging [14], atomic force microscopy (AFM) [15], circular dichroism spectroscopy (CD) [16] and X-ray diffraction [17].

Clearly, nucleation and fibril formation are largely dependent on $\mathrm{pH}$, temperature and electrostatic interactions. The large surface to volume ratio of nanomaterials is an attractive feature which facilitates their binding to monomers and/or fibrils and prevents further assembly [15]. Nanomaterials can either prevent the association of monomers and/or disturb fibrils or plaques via hydrophobic interactions (Figure 1B). Moreover, they can also induce conformational changes of monomers thereby preventing the aggregation/fibrillation processes [19]. Below we discuss nanomaterials which have been reported to inhibit the formation of several kinds of protein aggregates. 


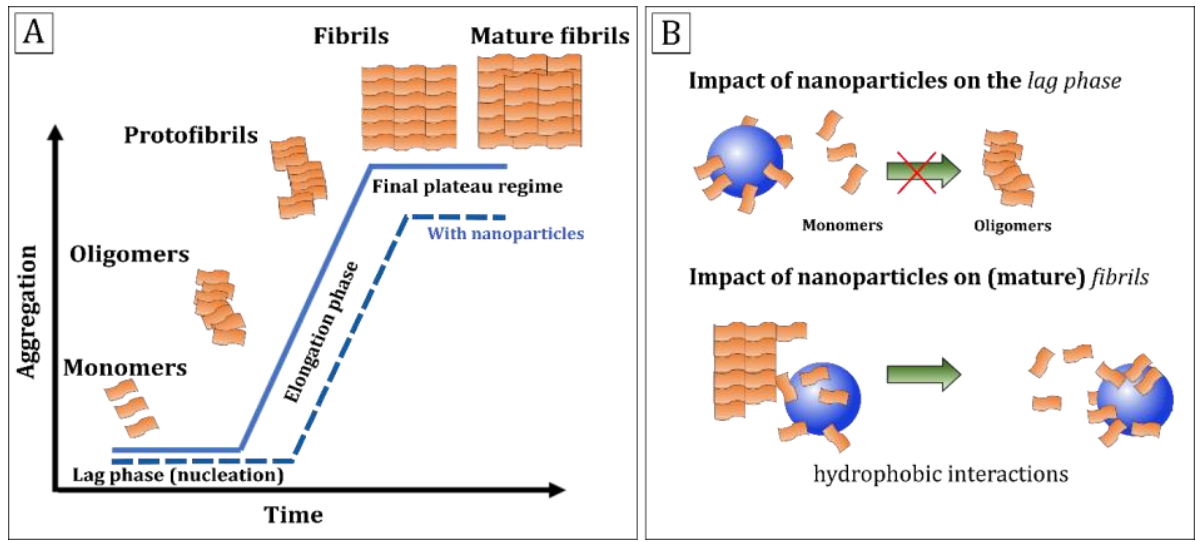

Figure 1. (A) Different phases of the formation of amyloid fibrils. This mechanism of fibril formation is found in most neurodegenerative diseases (adapted from [18]). (B) Interaction of nanoparticles with monomers and (mature) fibrils. The interaction with monomers may lead to a depletion of monomers in the bulk and retard the lag phase (dotted line in panel A). Through hydrophobic interactions, some nanomaterials can directly interact with mature fibrils (i.e. $\beta$ sheets) and disassemble them.

\section{$2.1 \quad$ Aß peptides in Alzheimer disease}

Alzheimer's disease (AD) is the major cause of dementia in elderly persons with poor therapeutic possibilities and bad prognosis. The main pathological hallmark is the extracellular deposition of plaques in the brain which primarily consist of amyloid beta (A $\beta)$ peptide. This peptide (consisting of 42 amino acids with a molecular weight around $4.5 \mathrm{kDa}$ ) can selfassemble into filamentous $\beta$-sheet aggregates (amyloid aggregates) in solution [20]. This has made in vitro investigations possible to assess the effect of nanomaterials on the fibrillation process [21]. 
Various types of nanomaterials have been studied to inhibit $\mathrm{A} \beta$ peptide aggregation in $\mathrm{AD}$, based on their capacity to bind monomers and oligomers either with specific ligands or via hydrophobic interactions (Figure 2). Following the idea of capturing A $\beta$ peptides, CabaleiroLago et al. described co-polymeric nanoparticles composed of $\mathrm{N}$-isopropylacrylamide (NIPAM) and N-tert-butylacrylamide (BAM) [22]. A clear lengthening of the lag time and $\mathrm{t}_{1 / 2}$ (half-time for fibrillation) was observed with 'pure' NIPAM nanoparticles while the presence of BAM in the copolymer required a higher concentration of nanoparticles to be efficient against the fibrillation process. The same team studied the effect of amino modified polystyrene nanoparticles on the $A \beta$ fibrillation [23]. The authors revealed that this kind of particles either inhibited or accelerated the fibrillation, depending on the concentration of the nanoparticles in solution. They especially stressed the impact of the surface area of nanoparticles on the fibrillation process. For instance, when the concentration of particles is high, the amount of peptides remaining in the bulk lowers, which slows down the fibrillation rate (Figure 2A). However, when the concentration of particles is low, fibrillation can still occur and even be promoted at the surface of the nanoparticles which acts as a catalyzer. Such in vitro observations are of importance as they show that for $\mathrm{AD}$ treatment, a strong control over the concentration of nanoparticles in the brain would be required. In this regard, understanding the pharmacokinetics and controlling the bio-distribution of injected nanomaterials would be highly challenging and of high importance. Moreover, there is no evidence for specificity towards $\mathrm{A} \beta$ peptides and these nanomaterials may interact with other biological targets in vivo, further compromising their efficacy.

Mahmoudi et al. further explored the effect of nanoparticles on fibrillation in a more complex medium. They observed that various types of nanoparticles (silica nanoparticles, $\mathrm{COOH}-$ terminated polystyrene nanoparticles and multi-walled carbon nanotubes) accelerate the rate of $\mathrm{A} \beta$ fibril formation [24]. The authors tried to functionalize the nanoparticles by incubating them 
with plasma proteins. They subsequently washed the nanoparticles to remove the loosely bound proteins, keeping the 'hard corona' i.e. the strongly bound proteins. Indeed it is now well known that after systemic administration, bare nanoparticles abundantly interact with blood proteins and get covered by a protein corona whose nature and composition varies according to the surface properties of the nanoparticles [25,26]. Interestingly, the authors showed that the presence of a protein corona on their nanoparticles could inhibit the fibrillation process, while bare (i.e. uncoated nanoparticles) accelerated surface-mediated fibrillation (Figure 2B). They explained that the protein corona creates a shell around the nanoparticles which reduces the access of $A \beta$ peptides to the particles thus slowing down the formation of fibrils, unlike naked nanoparticles on which the $A \beta$ peptides can attach and initiate fibrillation. However, in the conclusion of this study the authors remained careful regarding the benefits of this observation in vivo since it is known that $\mathrm{A} \beta$ oligomers are more toxic than mature $\mathrm{A} \beta$ fibrils and considered as being involved in the pathogenesis of Alzheimer disease [27].

The example above shows that the surface of nanomaterials plays a crucial role in the inhibition of the fibrillation of $A \beta$ peptides. As surface properties of nanomaterials can be tuned, this might allow to control the aggregation kinetics. Though, also the mobility of $\mathrm{A} \beta$ peptides on the material surface itself can affect the fibrillation process (Figure 2C). When the diffusion of $\mathrm{A} \beta$ peptides on the surface is high, they can concentrate which initiates fibrillation. This is especially the case on smooth surfaces. Tuning the surface roughness might thus allow to control, to a certain extent, the fibrillation process. This was illustrated by Shezad et al. who showed for various polymer coatings and microparticles (using single molecule tracking, atomic force microscopy and TfT fluorescence) that rough surfaces present obstacles which retard the two-dimensional diffusion of $\mathrm{A} \beta$ peptides and slows down surface-mediated fibrillation [28]. 
In addition to polymeric nanoparticles, the potential of other types of nanomaterials to inhibit $\mathrm{A} \beta$ peptide fibrillation has been studied as well. Cadmium telluride quantum dots (CdTe QDs) functionalized with $\mathrm{N}$-acetyl-L-cysteine were shown to be effective in inhibiting amyloid fibrillation at very low concentration (1-10 $\mathrm{nM}$ ) and at any stage (monomers, oligomers and fibrils) [29]. In later reports also graphene QDs [30] and graphene oxides (GO) [31,32] were shown to inhibit $A \beta$ peptide fibrillation. Nevertheless, these experiments were only performed in vitro.

Molecular chaperones (like heat shock proteins, apoE, clusterin) play a critical role in cell homeostasis, repairing and maintaining the functional conformation of proteins [33]. They were also described as having a protective role against neurodegenerative diseases [34,35]. Through their ability to bind exposed hydrophobic regions of denatured or unfolded proteins, chaperones can detoxify cells from toxic aggregates and promote a return to a normal protein homeostasis via proteasomal degradation. Taking inspiration from this, Huang et al. fabricated 'artificial chaperones' consisting of biocompatible, long circulating mixed shell polymeric micelles (MSPMs) with tunable surfaces (Figure 2D) [36]. These MSPMs were obtained by the selfassembly of two amphipathic diblock copolymers, namely poly(e-caprolactone)-blockpoly(ethylene-oxide) (PCL-b-PEG) and poly(e-caprolactone)-block-poly(Nisopropylacrylamide) (PCL-b-PNIPAM). At physiological temperature, PNIPAM chains collapse to form hydrophobic patches on the PCL core which facilitates the binding of A $\beta$ hydrophobic monomers and oligomers (Figure 2D). Interestingly, the authors reported that MSPMs can both inhibit A $\beta$ fibrillation and facilitate the degradation of MSPM-A $\beta$ complexes by proteases. Also, curcumin (CUR, which has affinity for amyloid structures) has shown promising results in vitro and in an Alzheimer mouse model to target and prevent A $\beta$ fibrillation [37]. Following these observations, gold nanoparticles functionalized with CUR were prepared. Since CUR is not water-soluble in its free form, authors decided to functionalize gold 
nanoparticles with it. CUR-gold nanoparticles were able to both retard fibrillation and dissolve amyloid aggregates in vitro, as observed by TEM imaging and TFT fluorescence measurements (Figure 2E) [38]. Another example of artificial chaperones are nanogels (around $30 \mathrm{~nm}$ in size) composed of the polysaccharide pullulan and cholesterol, which have been shown to bind exposed hydrophobic regions of denatured proteins in vitro [39]; such nanogels were also able to incorporate and change the conformation of $\mathrm{A} \beta$ peptides [40].

Other interesting features of nanoparticles that can be exploited to prevent protein aggregation are their chiral properties. Enantiomeric nanoparticles, can be for instance used for enantioselective crystallization of racemic mixtures [41] - which is of high interest in the pharmaceutical field. In the context of amyloid formation, it has been demonstrated recently that $\alpha$-helical intermediates are strongly involved in the fibrillation process and sensitive to chiral environments [42]. Therefore, chiral supramolecular complexes were investigated to inhibit $A \beta$ aggregation [43]. It has been shown, for instance, that chiral penicillamine-modified selenium nanoparticles (Pen@Se NPs) could affect intracellular fibrillation of A $\beta$ peptides (inside PC-12 cells) depending on their chiral properties [44]. D- Pen@Se NPs were shown to be effective to inhibit aggregation whereas L- Pen@Se NPs were not efficient. Interestingly, authors of this study reported notable ameliorations of mice cognition and memory impairments. Malishev et al. also applied this principle to Alzheimer's disease using enantiomeric carbon dots (Cdots) either synthesized from L-lysine or D-lysine as carbon sources [45]. They showed that L-lys-Cdots had better interaction with monomers and prefibrillar structures compared to D-lys-Cdots thereby affecting fibrillation and cytotoxicity.

In the attractive studies discussed above, most of the experiments were only carried out in vitro. Mostly, no or rather poor data were provided on the capacity of such nanomaterials to cross the blood-brain-barrier (BBB), being very crucial to score the therapeutic potential. Liposomes, 
being lipid-based nano-vesicles heavily used for drug delivery purposes, carrying CUR and functionalized with anti-transferrin antibodies as BBB targeting agents, were shown to prevent $\mathrm{A} \beta$ aggregation in vitro while they could label amyloid deposits in post-mortem brain tissues [46]. However, so far, these results have not been confirmed in vivo. In another report [47], liposomes functionalized with phosphatidic acid (PA) and a modified ApoE-derived peptide (a BBB targeting ligand) were shown to cross the BBB in an in-vitro BBB model. In vitro such liposomes also prevented $\mathrm{A} \beta$ peptide aggregation and disassembled preformed fibrils. Authors noticed a synergic effect between PA and ApoE since 'mono-functionalized' liposomes (i.e. PA-liposomes or ApoE-liposomes) did not show any effect. This is likely due to a preferential interaction of PA with cationic residues on the A $\beta$ peptide and, conversely, an interaction of ApoE with anionic residues. In mice, biodistribution studies revealed higher radioactivity in the brain for radiolabeled mApoE-PA-liposomes compared to PA-liposomes suggesting a better crossing of the BBB. Though no information on memory recovery (an indication for treatment efficacy) has been provided. 

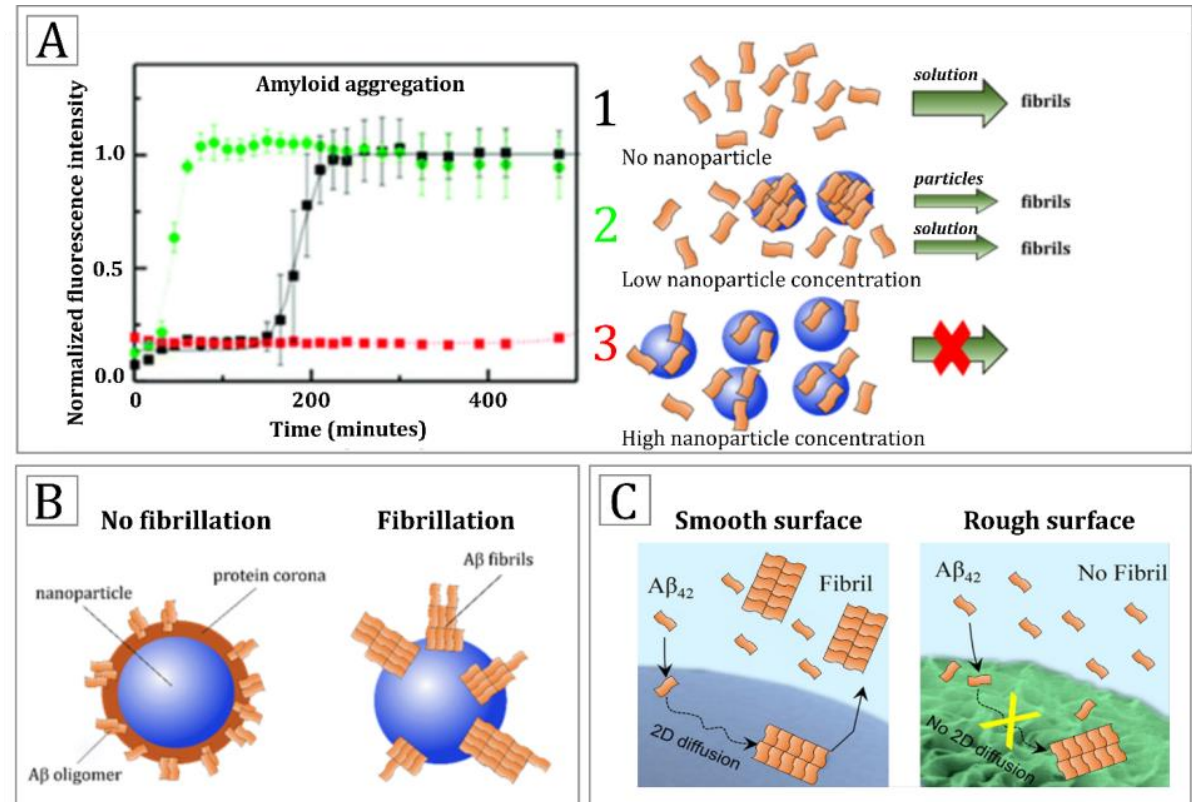

C Smooth surface Rough surface
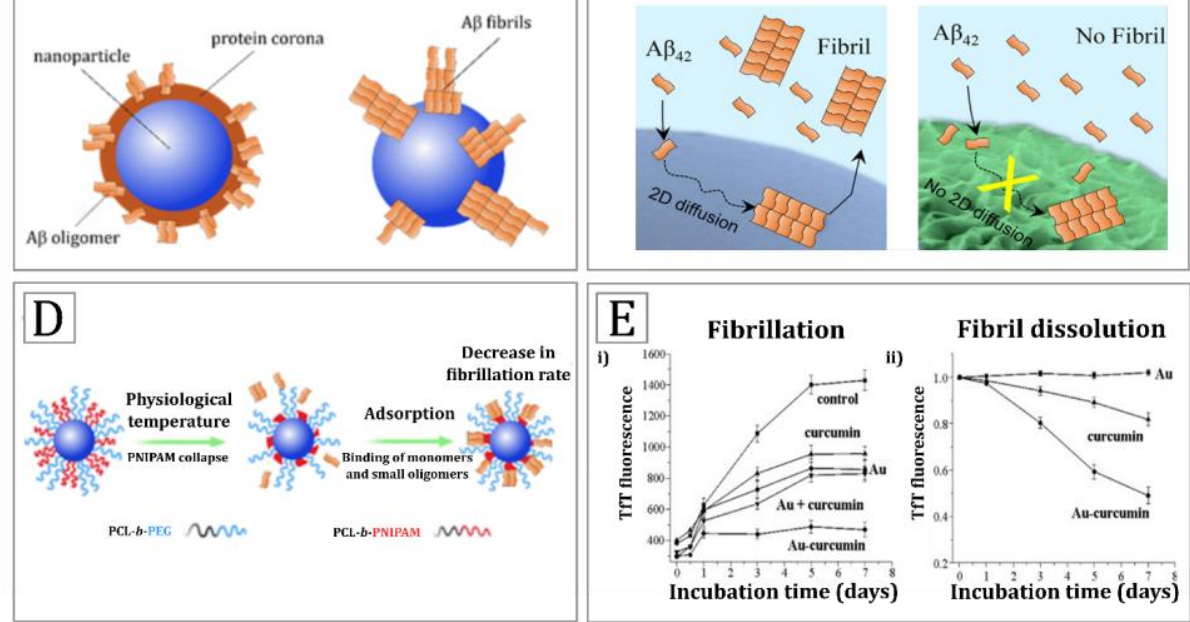

Figure 2. Aggregation of $\mathrm{A} \beta$ peptides can be influenced by different manners using nanoparticles. (A) The concentration of nanoparticles can impact $A \beta$ peptide aggregation in different ways. At a low nanoparticle concentration, the density of monomers at the surface of nanoparticles increases, which catalyzes the fibrillation. In addition, the monomers remaining in the bulk also initiate the fibrillation (green curve). Overall this leads to an acceleration of the fibrillation compared to free monomers (without nanoparticles) in solution (black curve). At high nanoparticle concentration, less monomers remain in the solution which inhibits the fibrillation (red curve). (B) Schematic representation of the impact of a protein corona on the 
fibrillation of A $\beta$ peptides (adapted from [23]). (C) Impact of the surface properties of materials on the fibrillation process (adapted from [28]). (D) Polymeric micelles as artificial thermoresponsive chaperones able to bind $A \beta$ monomers and oligomers (adapted from [36]). (E) TfT fluorescence measurements reflecting the impact of CUR-functionalized gold nanoparticles on (i) fibrillation and (ii) dissolution of $\mathrm{A} \beta$ fibrils (with permission from [38]).

\section{$2.2 \alpha$-synuclein in Parkinson disease}

In Parkinson and associated-diseases (synucleinopathies), $\alpha$-synuclein, a $14 \mathrm{kDa}$ protein whose role is still not elucidated, forms toxic amyloid fibrils in the midbrain in a similar manner as occurs in Alzheimer's disease. Various types of dendrimers, being nano-sized branched polymers with a radially symmetric 'tree-like' structure (Figure 3Ai), were extensively studied to prevent the formation of fibrils involved in Parkinson disease. Dendrimers [48] are of high interest in drug delivery thanks to their versatility and capacity to be conjugated to different kinds of molecules (biologically active compounds or targeting ligands). In vitro, polyamidoamine (PAMAM) dendrimers of three different generations (G4, G5 and G6) could avoid the fibrillation of $\alpha$-synuclein [49] through the amino groups at their surface which facilitate their interaction with $\alpha$-synuclein. Also, these dendrimers showed a capacity to decompose fibrillary aggregates. Phosphorus [50,51] and carbosilane [52] dendrimers similarly inhibited $\alpha$-synuclein aggregation (in buffer solutions). Interestingly, Laumann et al. evaluated the capacity of polypropylenimine dendrimers, either terminated with urea (PPI-U) or methylthiourea (PPI-MTU), to disassemble intracellular $\alpha$-synuclein aggregates [53]. Both types of dendrimers were able to solubilize aggregates present in human melanoma cells

(Figure 3Aii). PPI-MTU were found to be more efficient, though also more cytotoxic than PPIU. 
Curcumin has also a strong binding capacity to $\alpha$-synuclein in the non-amyloid- $\beta$ component region, preventing its aggregation [54]. Taebnia et al. developed amine-functionalized mesoporous silica nanoparticles (AAS-MSNPs) to encapsulate poorly-soluble drugs like CUR. The authors showed that $\alpha$-synuclein can absorb on CUR present at the surface of the silica nanoparticles thereby inhibiting the fibrillation process [55]. More recently, spectacular results were obtained with graphene quantum dots (GQDs) able to prevent $\alpha$-synuclein fibrillation and disassemble fibrils in vitro (Figure 3Bi and 3Bii). GQDs were shown to cross the BBB in vivo and bind mature $\alpha$-synuclein fibrils injected in the hemisphere of mice, thereby disaggregating them through hydrophobic interactions (Figure 3Biii and 3Biv) [56]. 

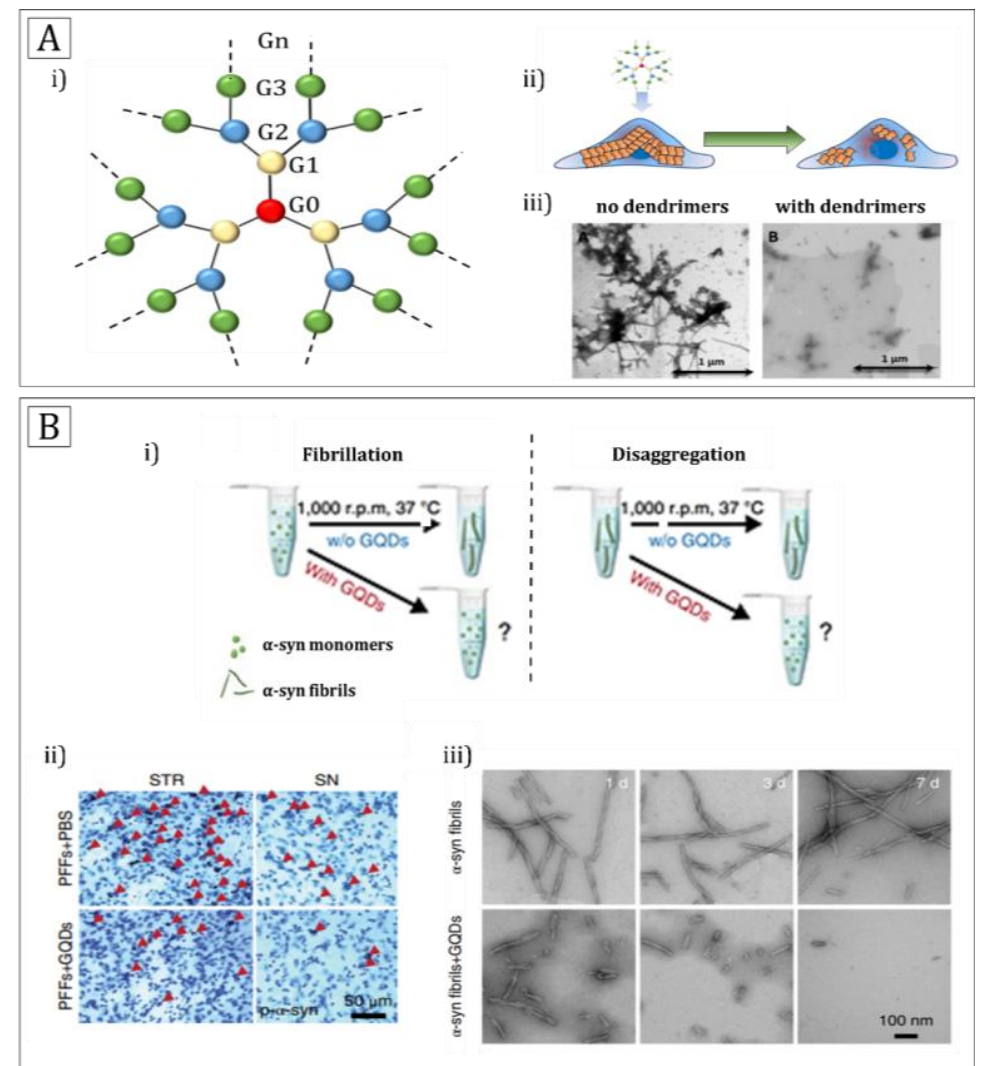

Figure 3. Several types of nanomaterials were reported to inhibit $\alpha$-synuclein fibrillation. (A) (i) Schematic representation of the structure of a dendrimer. Some dendrimers (PPI-U and PPIMTU) were shown to disassemble $\alpha$-synuclein aggregates in cells (ii) and in buffer (iii) (adapted from [53]). (B) (i) Schematic representation of the impact of GQDs on the fibrillation of $\alpha$ synuclein monomers and disaggregation of $\alpha$-synuclein fibrils. (ii) TEM images of fibrils treated or not with GQDs as a function of time (up to 7 days). (iii) Representative phosphorylated $\alpha$-synuclein (p- $\alpha$-syn) immunostaining images in the striatum (STR) and substantia nigra ( $\mathrm{SN}$ ) of $\alpha$-synuclein preformed fibrils (PFF) stereotaxically injected in the hemisphere. 


\subsection{Polyglutamine repeats in Huntington disease}

Huntington disease is an inherited disease involving the fibrillation of polyglutamine repeats into toxic intracellular aggregates. It is characterized by psychiatric, motor and cognitive alterations. Several sugars (maltose, glucose, sucrose, trehalose) can act as chemical chaperones in cells by stabilizing and restoring the folding of proteins [57] and can therefore be used to inhibit protein aggregation. For example, free trehalose has been shown to efficiently inhibit protein aggregation, not only in vitro but also in vivo with very promising results after oral administration in mice (Huntington disease model) [58]. It is assumed that trehalose can bind to expanded polyglutamines and stabilize amyloidogenic intermediates, therefore preventing further aggregation.

It was recently observed that, compared to 'molecular sugars', sugar-terminated nanoparticles are much more effective in inhibiting protein aggregation [59]. Zwitterionic poly(trehalose) nanoparticles of 20-30 nm with an iron oxide core were prepared and tested in vitro and in vivo in mice (Huntington disease model). Such nanoparticles were designed to have improved intracellular uptake and a strong capacity to bind huntingtin by the presence of 20-800 trehalose molecules on their surface. They were shown to prevent aggregation of huntingtin in cultured HD150Q cells (Figure 4A), with a thousand times higher efficacy compared to free trehalose and to cross the BBB and block huntingtin aggregation in the brain of HD mice at micromolar concentrations (Figure 4B) [60]. In another study, the same authors reported on iron oxide nanoparticles carrying amino-acid based osmolytes, like glutamine and proline, at their surface. They observed again that, compared to molecular glutamine and proline, nanoparticles showed a significantly (1000 to 10000 times) improved inhibition of the aggregation of the mutant 
huntingtin protein [61]. Note that molecular trehalose has also been shown to reduce the aggregation of $\mathrm{A} \beta$ peptides [62] and islet amyloid polypeptides (IAPP) [63].

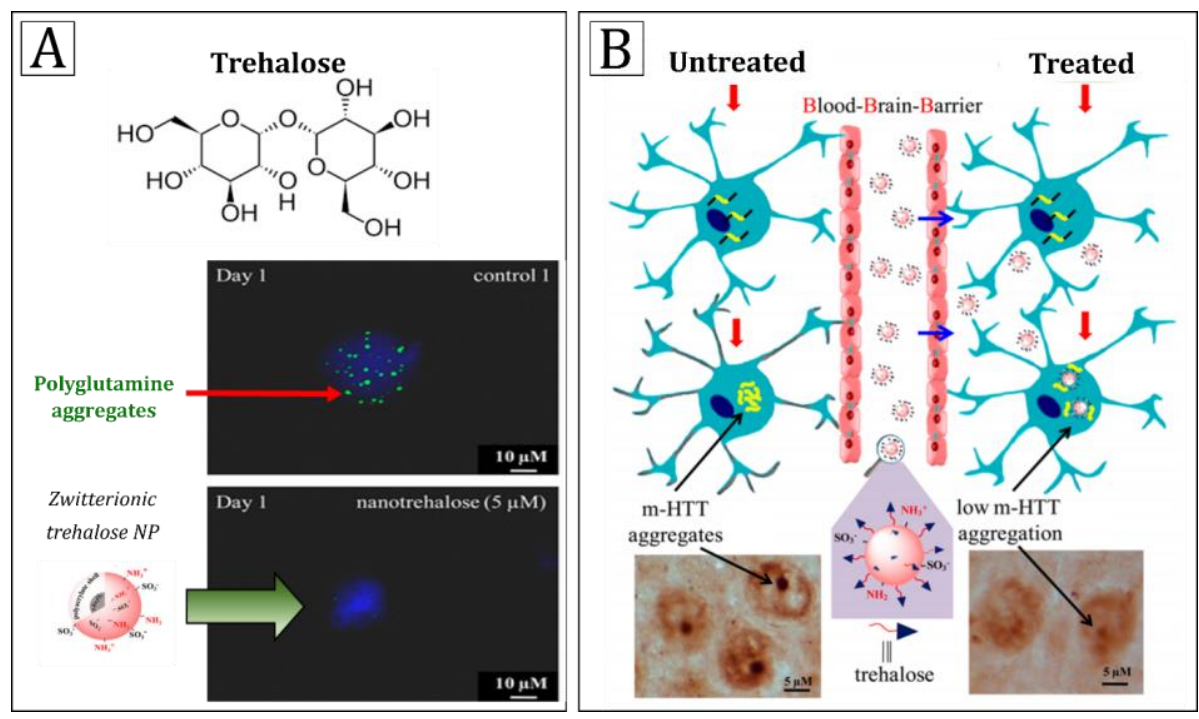

Figure 4. (A) Zwiterrionic poly(trehalose) nanoparticles were shown to prevent the aggregation of mutant GFP-tagged Huntingtin (in green) in cells. Nuclei were stained with DAPI (in blue). (B) Poly(trehalose) nanoparticles in a Huntington disease mouse model: nanoparticles flow through the blood, cross the blood brain barrier, enter neuronal cells in the brain, bind to polyglutamine containing mutant huntingtin (m-HTT) and block its aggregation. With permission from [60].

\subsection{Islet amyloid polypeptides and insulin in type 2 diabetes}

As described above, amyloid plaques formation is involved in neurodegenerative diseases, though similar processes have been described in diabetes mellitus, especially in type 2 diabetes. Mature islet amyloid polypeptide (IAPP; $4 \mathrm{kDa}$ ), which contains 37 amino acids, can form insoluble amyloid fibrils (islet amyloids; $\beta$-sheet structures as occur in Alzheimer's and 
Parkinson disease). These aggregates are believed to be cytotoxic and to be correlated with the loss of $\beta$-cells in the pancreas and failure of islet transplants [64]. Cabaleiro-Lago et al. studied the effect of NIPAM:BAM nanoparticles on the amyloid formation by IAPP (in vitro). As they observed previously for A $\beta$ peptides, 'pure' NIPAM nanoparticles showed the strongest inhibition of IAPP aggregation [65]. Generation 3 hydroxyl-terminated PAMAM dendrimers (PAMAM-OH) were also found to be effective in reducing the cytotoxicity of IAPP aggregates in NIT-1 and MIN6 cells and in mouse islets [66]. Moreover, dynamic light scattering and TEM revealed smaller aggregates while TfT measurements showed that PAMAM-OH dendrimers were able to stop the aggregation process up to 8 hours.

Repeated administrations of insulin can lead to the formation of subcutaneous amyloid deposits at the injection site, leading to poor glycemic control and insulin resistance $[67,68]$. In literature, the inhibition of insulin fibrillation has been described, in a concentration-dependent manner with carbon dots [69] and with silicon nanoparticles [70].

Using $\mathrm{Fe}_{3} \mathrm{O}_{4}$ magnetic nanoparticles coated with dextrans, Siposova et al. studied the influence of dextran chain length on insulin fibrillation and destruction of fibrils. While destruction of insulin fibrils was observed with larger dextrans $(70 \mathrm{kDa})$, particles coated with smaller dextrans (15-20 kDa) showed higher inhibition against amyloid fibrillation (Figure 5A). The authors explained that the efficacy in inhibiting the fibrillation process by the smaller nanoparticles is likely due to their higher surface/volume ratio which favors the binding of monomers and thus lowers the concentration of free insulin in the bulk [71]. With larger particles, authors explain that many side-chain interactions with $\beta$-sheets structures highly contribute to their destruction

While a common strategy is to prevent the fibrillation and/or destroy existing aggregates, changing the morphology of fibrils with the aim to reduce their toxicity is another original 
approach. Using poly(2-hydroxyethyl acrylate) (PHEA) star polymers, Pilkington et al. succeeded in forming aggregates with a new morphology that they named "stelliform amyloids" as studied by atomistic molecular simulations (Figure 5B). The authors revealed an interesting correlation between PHEA stars mediated aggregation and a reduction of IAPP-mediated toxicity in pancreatic cells and islets [72].

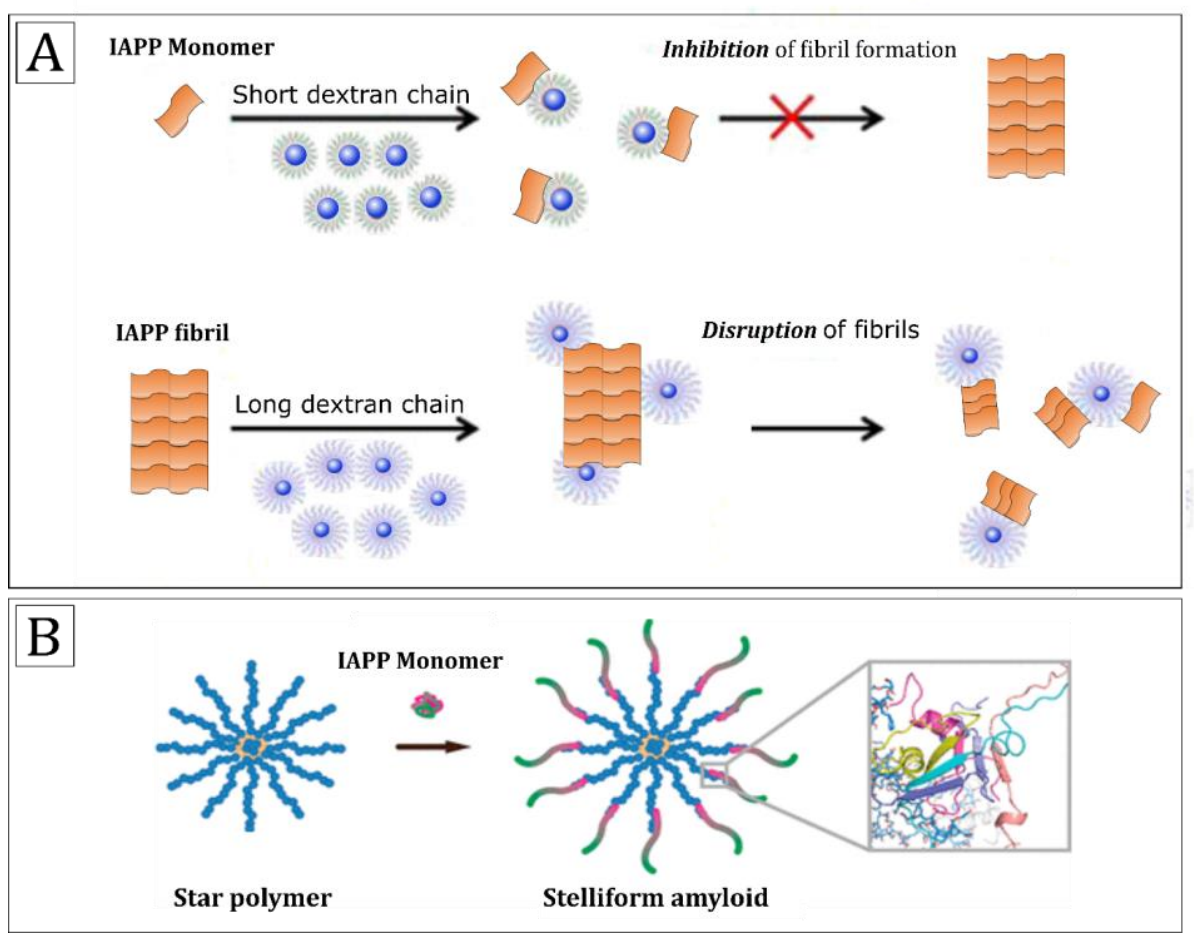

Figure 5. (A) Schematic representation of dextran coated nanoparticles either inhibiting insulin amyloid aggregation or destroying the aggregates (adapted from [71]). (B) Star polymers can induce the formation of islet amyloid polypeptide (IAPP) aggregates with a new morphology which are less toxic for pancreatic cells and islets (with permission from [72]). 


\subsection{Collagen fibrillation}

Type I collagen is the most abundant protein in connective tissues. Self-assembly of collagen molecules into triple helixes is a crucial biological phenomenon to ensure the cohesion and maintenance of tissues and organs. On the other hand, collagen fibrillation is also involved in several disorders such as for example heart diseases, thrombosis and restenosis. Impacting collagen fibril formation is of high interest to reduce fibrosis. In fact, several attempts to block type I collagen self-assembly using monoclonal antibodies have been reported in the context of fibrosis inhibition $[73,74]$ but only few examples involving nanomaterials are described. Based on the structure and constitutive amino acid sequence of collagen, Anand et al. designed AuNPs functionalized with hydroxyproline that are able to specifically recognize a sequence in the structure of type I collagen (in vitro), leading to binding and suppression of collagen fibril formation which might pave the way for reducing tissue fibrosis [75]. Wilson et al. showed that different effects could be observed on collagen fibrillation in vitro as a function of the charge of nanoparticles coated with polyelectrolytes. While negatively charged gold nanorods accelerated the fibrillation, positively charged particles could delay it [76].

\subsection{Reflection on the surface characteristics for efficient inhibition of protein aggregation}

From all the examples described in the previous sections, we have listed several types of surface that have shown an effect on protein aggregation (Table 1). Though this list is not exhaustive, we can conclude that nanoparticles with a rough and hydrophobic surface showed promising results. It appears that non-functionalized nanoparticles have interesting characteristics although they can be opsonized after intravenous injection. The functionalization of nanoparticles have also shown promising results via specific targeting of aggregates but does not seem to be indispensable. It is also worth noting that there are no or few examples of pegylated nanoparticles - highly likely because the steric hindrance does not allow an optimal 
interaction with the aggregates - and also because the formation of a protein corona can facilitate the inhibition [24]. It seems, that each type of material can have a different effect depending on the nature of the aggregates. This is also highlighted in the case of chiral particles for which one enantiomer is more active than the other [44,45]. Similarly, some particles can slow down the aggregation of one type of aggregate whereas it accelerates it in other situations [77]. Also, it appears that there is no clear establishment of the role of the surface charge since both positively and negatively charged particles can have an effect. 
Table 1. Summary of the different types of surface of nanomaterials commonly used to prevent protein aggregation.

\begin{tabular}{|c|c|c|c|}
\hline Surface features & Type of materials & Target proteins & References \\
\hline Chiral & $\begin{array}{l}\text { - Carbon dots } \\
\text { - Penicillamine- } \\
\text { modified selenium }\end{array}$ & $\mathrm{A} \beta$ peptides & {$[44,45]$} \\
\hline Rough & $\begin{array}{l}\text { - Polystyrene } \\
\text { nanoparticles }\end{array}$ & $\mathrm{A} \beta$ peptides & [28] \\
\hline Zwitterionic & $\begin{array}{l}\text { - Trehalose } \\
\text { nanoparticles }\end{array}$ & Polyglutamine & {$[60]$} \\
\hline \multirow[t]{3}{*}{$\begin{array}{l}\text { Functionalized (e.g: } \\
\text { ligands, amino-acids) }\end{array}$} & $\begin{array}{ll}\text { - } & \text { Dextran-coated } \\
\text { IONPs } & \\
\text { - } & \text { Curcumin- } \\
\text { functionalized } & \text { silica } \\
\text { NPs } & \\
\text { - } & \text { Tyrosine and } \\
\text { tryptophan } & \\
\text { funtionalized AuNPs }\end{array}$ & IAPP & {$[55,71,78]$} \\
\hline & $\begin{array}{l}\text { Hydroxyproline- } \\
\text { coated AuNPs }\end{array}$ & Collagen & {$[75]$} \\
\hline & $\begin{array}{l}\text { - Glutamate and } \\
\text { proline } \\
\text { functionalized } \\
\text { IONPs }\end{array}$ & Polyglutamine & {$[61]$} \\
\hline
\end{tabular}

\section{Clearing peptide monomers and removing protein aggregates with nanomaterials}

As discussed above, several studies report on various types of nanomaterials to inhibit plaque formation. It is highly important to keep in mind that most of these experiments were performed 
in vitro. While the outcome of all this work is substantial and attractive, it remains (very) early stage. Indeed, most of the time, information on (i) the capacity for such nanomaterials to efficiently cross the BBB and (ii) their safety in vivo is not provided. Moreover, it is not completely sure that these nanomaterials will show similar effects if they are not acting in a 'pure system' containing only one aggregating peptide or protein. This is why other strategies are explored to remove or disturb equilibria between peptides and aggregates.

\subsection{Disturbing the equilibrium between fibrils and monomers}

In the case of Alzheimer's disease, another strategy has emerged to prevent plaque formation and lies on the reduction of deposits in the brain by the clearance of circulating plasmatic $\mathrm{A} \beta$ monomers through a peripheral sink (Figure 6A) [79]. This approach thus focuses on the equilibrium between $\mathrm{A} \beta$ peptides in plasma and brain [80,81]: clearing peripheral $\mathrm{A} \beta$ monomers (i.e. by liver degradation) will disturb the equilibrium and lower the amount of $\mathrm{A} \beta$ monomers in the brain without the need for nanoparticles to cross the BBB, which is a very strong advantage of this approach.

Following this concept, Carradori et al. designed biodegradable PEGylated nanoparticles composed of poly[hexadecyl cyanoacrylate-co-methoxypoly(ethylene glycol) cyanoacrylate], being well studied for drug delivery purposes [82], functionalized with anti $A \beta$ peptide monoclonal antibodies. In the blood of mice, such nanoparticles were able to bind circulating $A \beta$ peptides which were subsequently cleared from the circulation through common elimination pathways, reducing A $\beta$ peptide aggregation in the brain. Spectacularly, this led to a significant memory recovery in mice without the need to reach the central nervous system [83]. In another report, liposomes functionalized with a modified human ApoE-derived peptide and phosphatidic acid were shown to be able to clear $\mathrm{A} \beta$ peptides in an in vitro $\mathrm{BBB}$ transwell model consisting of an apical (blood) and basolateral (brain) compartment separated by a 
monolayer of brain microvascular endothelial cells. Such liposomes could also increase the concentration of $\mathrm{A} \beta$ monomers in plasma after injection in mice [84].

Knowing that apolipoprotein E3-reconstituted high density lipoprotein (ApoE3-rHDL) exhibits high affinity for $\mathrm{A} \beta$ monomers and oligomers, Song et al. proposed to accelerate their clearance using biomimetic ApoE3-rHDL nanoparticles prepared by self-assembly between DMPC vesicles and lipid-free Apo3 protein. The authors showed that such particles could facilitate liver and glial degradation of bound monomers. In vivo, intravenously-injected ApoE3-rHDL nanoparticles were shown to cross the $\mathrm{BBB}$ and to reduce amyloid deposition via $\mathrm{A} \beta$ degradation in the glial cells and rescue memory in mice [85].

Recently, a 'self-destructive nanosweeper', consisting of a chitosan core functionalized with two peptides (KLVFF able to bind A $\beta$ peptides and Beclin1 able to induce autophagy) has been reported. As illustrated in Figure 6B, such particles carrying the $A \beta$ monomers can be internalized in cells and trigger autophagy for their own destruction and clearance, thus allowing depletion of the A $\beta$ monomers [86]. This autophagy-mediated destruction of nanosweepers was shown to lower the amount of $\mathrm{A} \beta$ peptides in the brain. As a result, memory could be rescued in mice which was attributed to less amyloid deposits in the brain. Nevertheless, the authors explain they needed to use cyclosporine (a BBB permeability enhancer) to study the effect of the intravenously injected nanosweepers in the brain. Only $2 \%$ of the total injected dose of nanosweepers was found in the brain of mice after sacrifice. This again underlines the difficulty of reaching the brain after systemic injection, a clear limitation for the treatment of neurodegenerative diseases with nanoparticles. 


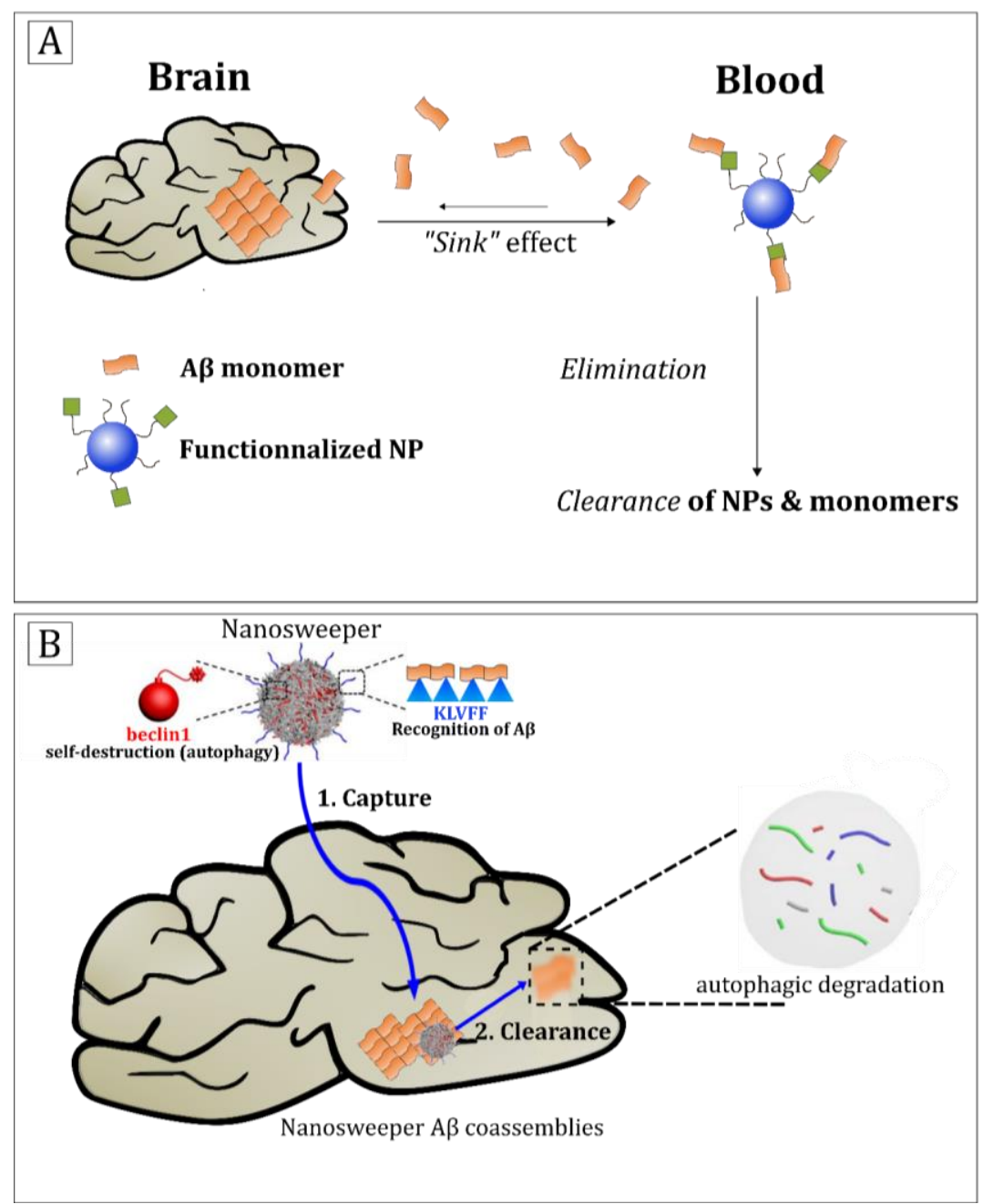

Figure 6. (A) Clearance of circulating plasmatic $A \beta$ monomers using functionalized nanoparticles (NPs). Thanks to the elimination of the nanoparticles carrying A $\beta$ monomers, a 'sink' effect is induced that displaces the equilibrium and contributes to the destruction of amyloid deposits in the brain. (B) Schematic representation of the concept of 'nanosweepers'. This type of nanoparticle can recognize and bind $A \beta$ monomers and trigger autophagy of 
hyppocampal neurons after being internalized by cells. This creates a local depletion of A $\beta$ monomers which eventually alters amyloid plaques in the brain (adapted from [86]).

\subsection{Magnetic removal of fibrils}

Early diagnosis of neurodegenerative diseases is the key for efficient prevention of lethal complications. Visualizing plaques with imaging agents (like gadolinium), to determine their location, could give precious information for early diagnosis [87] . Also, the detection of low concentrations of $\mathrm{A} \beta$ peptides in plasma is of high interest [88].

For the purpose of fluorescence and magnetic imaging of A $\beta 40$ fibrils, Skaat et al. designed fluorescent maghemite nanoparticles $\left(\gamma-\mathrm{Fe}_{2} \mathrm{O}_{3} \mathrm{NPs}\right)$. Although such nanoparticles did not have any effect on the fibrillation kinetics, they allowed fluorescence staining of fibrils in vitro and easy removal from the aqueous phase with a simple magnet [89]. Though these results were original, magnetic removal of plaques from the brain remains of course highly questionable since no information is given regarding the (i) capacity of $\gamma-\mathrm{Fe}_{2} \mathrm{O}_{3}$ NPs to cross the BBB and (ii) the capacity of magnets to move plaques in the brain.

\section{Destroying peptide and protein aggregates with stimuli-responsive nanomaterials}

\subsection{Electromagnetic irradiation and magnetic heating}

If the use of microwaves in combination with gold nanoparticles has been intensively explored for cancer hyperthermia and to improve the effect of chemotherapeutics [90], it can also be harnessed to destroy protein aggregates. Bastus et al. proposed to apply this strategy to Alzheimer's disease to locally destroy A $\beta$ deposits using gold nanoparticles functionalized with a targeting peptide (AuNP-cys-PEP). When exposed to a weak microwave field, AuNPs could heat up and destroy the aggregates. Upon 8 hours of irradiation with a weak microwave field, 
$\mathrm{A} \beta$ deposits were dissolved in vitro without any bulk heating (Figure 7A) [91]. However, such a long exposure time cannot be envisaged for in vivo applications.

The same strategy was employed by the same group on prefibrillar intermediate amyloidogenic aggregates (PIAA) which are known to assemble and form fibrils [92]. After incubating PIAA with AuNP-CLPFFD and irradiation with weak microwaves, no fibril formation could be observed, whereas without irradiation (i.e only with AuNP-CLPFFD), fibril formation occurred.

Besides microwaves, also alternating magnetic fields combined with inorganic nanoparticles (like iron oxide particles) have been widely studied (and clinically used [93]) in cancer therapy (hyperthermia) [94]. In the context of protein aggregation, a few studies have explored this strategy using magnetic particles to destroy blood clots. Indeed, fast destruction of blood clots is a major challenge in medicine to achieve reperfusion of affected tissues after acute stroke. Tissue plasminogen activator (tPA) is one of the most used medication for the treatment of acute ischemic stroke. However, tPA treatment is often associated with intracranial hemorrhage [95]. To reduce undesired effects, nanoconstructs were prepared by immobilizing tPA on 20 nm iron oxide nanocubes surrounded by albumin (Figure 7Bi). The mixture of tPA and albumin strongly stabilizes the nanoconstructs and prevents leakage of tPA, thus limiting unwanted side effects. By direct contact with the fibrin network, an improved dissolution of blood clots in vitro could be observed (100-fold faster dissolution as compared with free tPA) which authors attributed to a specific interaction between albumin and the fibrin network (Figure 7Bii). When exposed to an alternating magnetic field, such iron oxide based nanoconstructs could further enhance clot dissolution rates via thermal lysis (10-fold) [96]. 

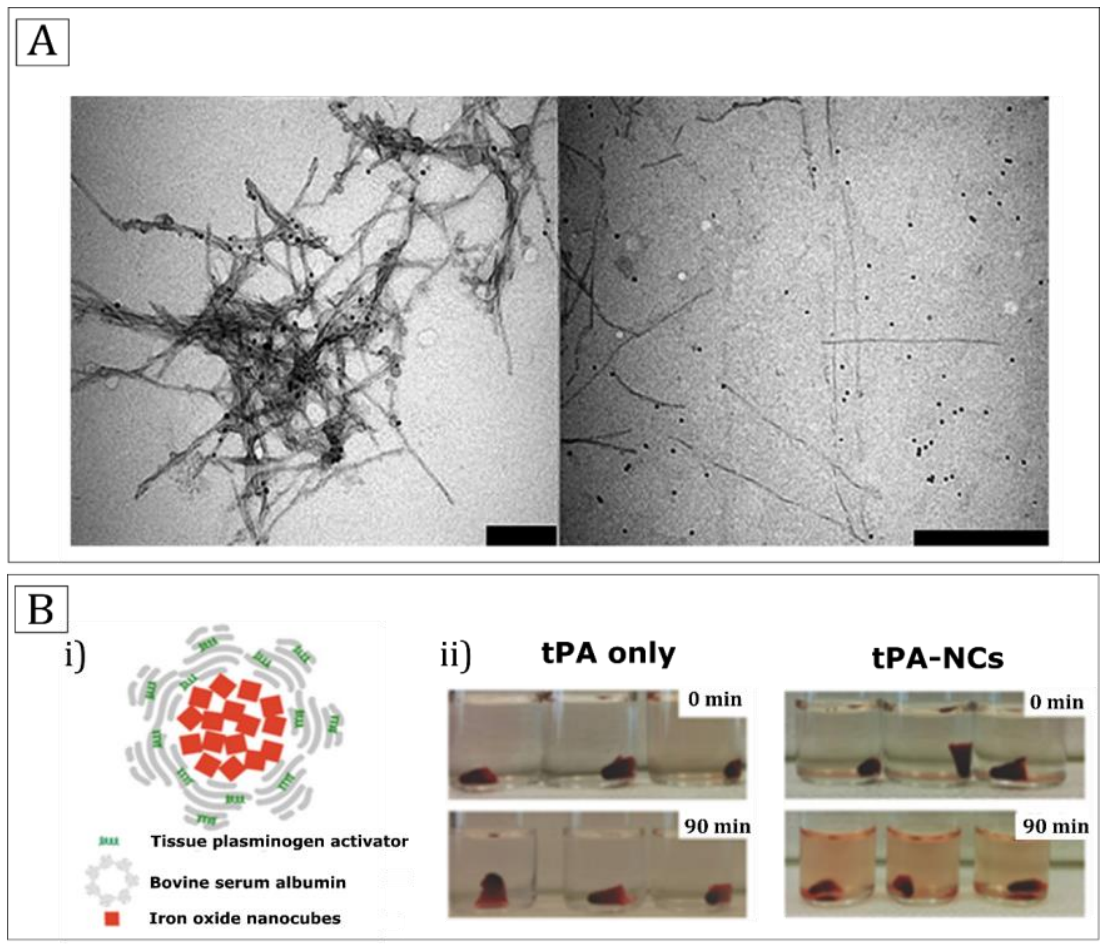

Figure 7. (A) Left: electron microscopy image of gold nanoparticles (functionalized with targeting ligands) bound to A $\beta 1-42$ aggregates. Right: electron microscopy image after irradiating the aggregates for 8 hours with a weak microwave magnetic field. Bars are $500 \mathrm{~nm}$. With permission from [91]. (B) (i) tPA nanoconstructs (tPA-NCs) were shown to improve dissolution rate of blood clots (ii) which could be further improved when an alternate magnetic field was applied (adapted from [96]).

\subsection{Ultrasound and microbubbles}

Also ultrasound (US) energy and microbubbles (MBs; typically composed of a lipid or polymeric shell and a gaseous core) are attractive to destroy blood clots. Bursting such MBs upon applying ultrasound might provide sufficient mechanical energy to release encapsulated 
drugs and break nearby blood clots. The combined use of MBs, ultrasound and tPA has indeed been studied in vitro and in vivo (rabbits) in a stroke model [97]. The authors showed that tPA doses can be reduced (up to 5-fold) to achieve significant clot loss in the presence of MB and ultrasounds. In vivo, the combination of MBs and tPA showed a significant decrease in infarct volume compared to controls. As far as we know, the use of microbubbles and ultrasound to break pathological protein aggregates (other than blood clots) has not been explored.

\subsection{Light}

Carbon-based nanomaterials are known to absorb near infrared light making them good candidates for photothermal therapies and destruction of protein aggregates. Yang and coworkers reported that graphene oxide nanosheets modified with thioflavine S (a dye that specifically binds to $A \beta$ fibrils), upon exposure to near infrared (NIR) light, could dissociate fibrils in buffer and ex vivo in cerebrospinal fluid collected from mice through hyperthermic effects [98].

An interesting feature of metallic nanoparticles -especially noble metals- is their plasmonic properties and their capacity to absorb light at different wavelengths as a function of their size and shape. For instance, (negatively charged) 1,2-dimyristoyl-sn-glycero-3-phosphocholine (DMPC) coated gold nanorods were shown to easily bind to the cationic amyloid sequence of A $\beta$ peptides. On the one hand, such particles could inhibit amyloid fibrillation when added during the early stage of fibrillation. On the other hand, when these particles were added to mature fibrils and NIR laser light was applied for some minutes, a thermal dissociation of the fibrils could be achieved [99]. In another work, Triulzi et al. showed that a targeted photothermal ablation of amyloid plaques was possible using a preferential interaction between amyloid deposits and AuNPs functionalized with truncated $\mathrm{A} \beta$ peptides. Exposing amyloid aggregates in vitro with continuous laser light resulted in their photothermal ablation whereas 
non functionalized particles did not bind the aggregates and therefore could not ablate them after light exposure [100]. Interestingly, the ablation of plaques could only be observed at the site of irradiation with minimal thermal effects in surrounding areas.

It is known that AuNPs quickly heat up upon pulsed-laser light exposure, being attractive for photothermal therapies [101]. Also, under appropriate conditions, irradiating AuNPs with pulsed-laser light results in the formation of vapor nanobubbles (VNBs) due to the evaporation of water which surrounds the gold nanoparticles. The burst of such VNBs provides mechanical energy which is sufficient to, for example, transfect cells with different cargos by transient pore formation in the plasma membrane [102]. Though they did not mention the formation of VNBs, Lin et al. showed that femtosecond pulsed laser illumination of AuNPs allows to destroy amyloid plaques in vitro. Thanks to their plasmon properties, the illumination of gold nanorods $(800 \mathrm{~nm})$ with a femtosecond laser can induce their fragmentation (named explosion by the authors) which provides sufficient mechanical force to fragment $A \beta$ fibrils as observed by atomic force microscopy [103] (Figure 8A).

The very local increase in temperature may be also of interest to control the structure and folding/unfolding of proteins; indeed, Kang et al. reported that in the immediate adjacent environment of AuNPs illuminated with a pulsed-laser, proteins can be denatured [104]. This interesting feature could find applications to treat diseases involving protein unfolding and aggregation. Though such strategies may be promising, one must keep in mind that (i) surrounding tissues may be heated as well, leading to unwanted effects and (ii) the fragmentation of fibrils may generate toxic fragments.

All previous examples concern in vitro research and are difficult to evaluate in clinical experiments, especially due to the limited penetration of light in the body. As the eye is easily accessible to both light and advanced materials, our group has an interest in photothermal 
treatment of ophthalmological diseases. Recently we explored to which extent VNB may be suitable to destroy vitreous opacities (also named 'floaters') [105] (Figure 8B). Eye floaters are protein aggregates mostly composed of a mixture of different types of collagen that are present in the vitreous [106,107]. We synthesized hyaluronic acid-coated AuNPs which exhibited high mobility in vitreous and bound collagen fibers to selectively generate VNBs on eye floaters and were able to 'photo-ablate' them allowing a preservation of the surrounding vitreous. However, in vivo toxicity studies still need to be performed.

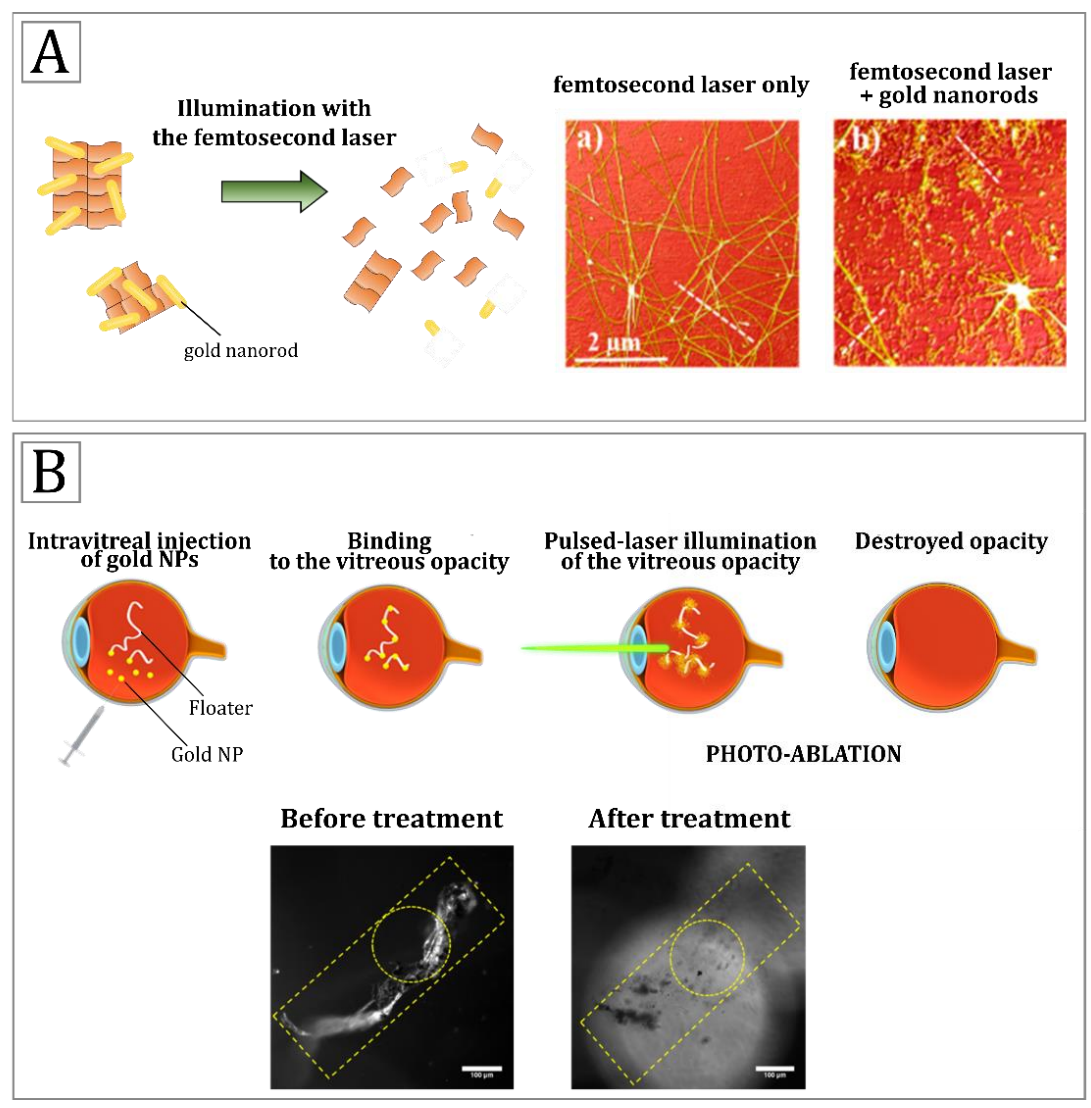

Figure 8. (A) After illumination with a femtosecond laser amyloid fibrils can be broken thanks to the explosion of gold nanorods. Atomic force microscopy (AFM) observations showed fibrils 
were destroyed (adapted from [103]). (B) Top: principle of photo-ablation of vitreous opacities. After intravitreal injection, gold nanoparticles can diffuse and bind floaters. Pulsed-laser illumination of the vitreous opacities induced the generation of vapor nanobubbles which will burst and destroy the opacities. Bottom: dark field microscopy image of a floater obtained after vitrectomy of a patient treated with $10 \mathrm{~nm}$ HA-AuNPs respectively before and after illumination with a nanosecond laser ( 3 pulses of $800 \mu \mathrm{J}$ (adapted from[105]).

\section{Toxicity and biodistribution of nanomaterials}

In this part, we will discuss and reflect on toxicity concerns and distribution of nanomaterials used to avoid or destroy protein aggregates. Since the toxicity of materials is not the scope of this review, we will restrict this part to materials that showed the most relevant results in the context of protein aggregation.

We have shown that several types of nanomaterials could efficiently contribute to avoid or destroy protein aggregates alone or in combination with stimuli. Important, however, is to stress on the toxicity and safety profile of such materials considering that biocompatibility and biodegradability are two major requirements for further clinical use. Whereas some examples highlighted in this review refer to liposomes - for which safety profile and toxicity have been already shown for many years - the safe use of inorganic nanoparticles is still not clearly established [108]. This is especially the case with gold nanoparticles whose toxicity and biodistribution differ according to their size, shape and surface charges. For example, smaller gold nanoparticles $(<5 \mathrm{~nm})$ have been reported to be toxic binding to DNA strands [109]. This is of major importance, especially with the use of pulsed lasers as we have previously discussed for the treatment of vitreous opacities or amyloid plaques (see section 4.3). It is indeed known that after such laser irradiations, gold nanoparticles can fragment [110] and therefore have reduced size which can be harmful - a strong control and further investigations on this process 
are therefore required before any clinical use. Quantum and carbon dots also appeared to be attractive, especially as we have seen that they could avoid the formation of $\alpha$-synuclein aggregates in the brain and show nice results in mice [56]. Compared to IONPs, that are already approved for clinical use [111], no clear toxicity profile was established with graphene quantum dots or carbon dots. Extensive efforts therefore remain for a better understanding of the biodistribution and the toxicity of such materials which can be modulated according to their surface properties (cite).

Various polymers have shown interesting results. One of the first work reporting on the use of polymer nanoparticles and protein aggregation from Cabaleiro-Lago et al. [22], was with NIPAM nanoparticles. This type of polymer nanoparticles was then studied several times in different context of protein aggregation and for drug delivery purposes. This polymer has been shown to be safe in vitro in several cell lines [112] and showed relative toxicity in others depending on the preparation methods [113]. In rabbits, its use as an ocular bioadhesive did not show toxicity [114]. However, it appears that some studies on biodegradation and biodistribution are still lacking and that other polymers have supplanted this one for drug delivery applications. Therefore, studying the anti-aggregation properties of polymers with known toxicity or approved for human use will be convenient.

It is now well-established in the drug delivery community and beyond that PEGylated nanoparticles allow a prolongation of residence in the bloodstream through decreased interactions with blood proteins. Important, however, would be to find a balance between blood circulation time (which will increase the likelihood of the particles to bind the aggregates) and the interaction of such nanomaterials with aggregates after intravenous injections. Indeed, one can assume that PEGylated particles - due to steric hindrance - have none or poor interaction with amyloids. This also explains why there are no or poor examples of pegylated nanoparticles 
that have been studied for the inhibition of fibrillation. Other strategies that allow a prolongation of time in the blood stream without affecting binding to protein aggregates are therefore needed. For instance, studying different shapes of nanoparticles in terms of inhibition of aggregation could be interesting - knowing that different shapes have also been reported to increase the circulation time in blood [115].

\section{Conclusions}

We reviewed the main nanotechnology based concepts and materials under investigation to prevent and fight the aggregation of proteins in a pathological context. If other strategies involving compounds of different nature have shown promising results against protein aggregation (e.g.: polyphenols [116], tetracyclines [117] or specific antibodies [118]), nanomaterials are still intriguing especially through their capacity to adsorb proteins on their surface to allow a control on their aggregation. Besides, their surface can be tuned specifically for this purpose, which is a clear advantage over bulk materials. However, it appears clearly that there is an important lack of animal studies as, indeed, most concepts are so far only investigated in vitro or ex vivo. To further explore nanomaterial-based approaches to prevent protein aggregation and/or destroy aggregates in the context of neurodegenerative diseases, designing nanomaterials able to access the central nervous system still remains a huge challenge. The use of external stimuli to interfere with protein aggregation/aggregates, like light or ultrasound, also raises the challenge of reaching the aggregates in the human body with those stimuli, which especially in the case of light poses problems due to limited tissue penetration (with the exception of aggregates in the eye). There is a strong necessity to be able to image and detect protein aggregates in the body; those expectations could be met, for example, by innovative (nano)theranostic approaches. Important to note as well is that in several studies it 
appeared that amyloid intermediates are even more toxic than mature fibrils or plaques $[119,120]$. One could thus assume that maintaining a high amount of monomers and/or oligomers (either by blocking the fibrillation or disassembling aggregates) could induce high toxicity as well. This phenomenon must be taken into consideration, especially in the case of Alzheimer's disease. Also, further studies are needed to get better insights in the fate of protein aggregate fragments which arise after the application of stimuli (light, heat, ultrasound). Especially to know is whether such fragments may form fibrils/aggregates again i.e. whether the destruction is reversible or not. Moreover, there is a clear lack of information regarding the nature of the fragments - as there is no indications on whether there are in the molecular state or consist in smaller aggregates. There is a clear need for further studies to clarify this point which for the moment remains a major issue. Clearly, the reviewed literature demonstrates that there is still a long way to go to provide promising nanotechnology based strategies to prevent in vivo protein aggregation or destroy protein aggregates. A better understanding of both the pathogenesis as well as the biophysical behavior of nanomaterials in complex biological environments remains highly needed to make next steps towards efficient and original therapies. Indeed, most of the nanoparticles reported to inhibit protein aggregation are studied in buffers which often occults important physiological aspects such as stability in biofluids (e.g. blood), biocompatibility and pharmacokinetics. It is clear that the problems inherent in the control of protein aggregation are finally close to those of the field of drug delivery - and more generally to the one of nanomedicine - with a strong need to adapt materials to human physiology.

\section{Funding}

This research did not receive any specific grant from funding agencies in the public, commercial, or not-for-profit sectors. 
Declarations of interest: none.

\section{Authors biography}

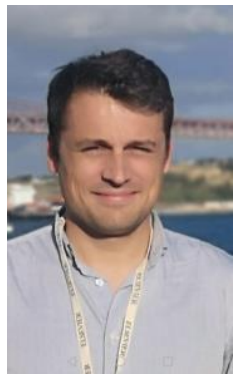

Félix Sauvage received his pharmacy degree in 2013 at the University of Rouen, France. The same year, he obtained his Master's degree in Pharmaceutical Technology and Biopharmaceutics at University Paris-Saclay and a fellowship from the French Ministry of Higher Education and Research. He joined the Institut-Galien Paris-Sud (University ParisSaclay, France) for a PhD. In 2017, Félix Sauvage joined the Laboratory of General Biochemistry and Physical Pharmacy at Ghent University as a postdoctoral research scientist. His research is situated at the interface between drug delivery, material sciences, biophysics and biology. 


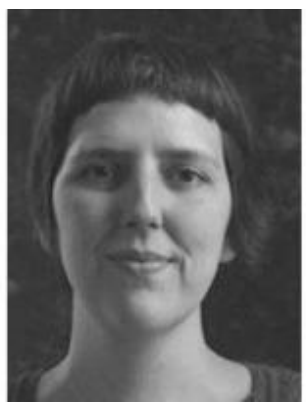

Katrien Remaut graduated as a Pharmacist at Ghent University in 2001. She then started her $\mathrm{PhD}$ in the Lab of General Biochemistry and Physical Pharmacy under guidance of Prof. De Smedt and Prof. Demeester. In 2007, she received the title of Doctor in Pharmaceutical Sciences and continued research work as a postdoctoral fellow of the Research Foundation Flanders. In 2013, Katrien was elected as member of the Young Academy in Flanders. She was appointed tenure track professor at the Lab General Biochemistry and Physical Pharmacy of Ghent University in 2014. Her research focuses on ocular gene delivery and peritoneal carcinomatosis.

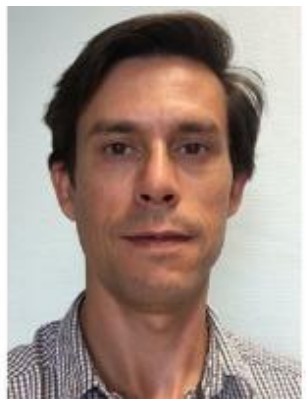

Kevin Braeckmans obtained a Master's Degree in Physics at Ghent University in 1999. Next, he joined the Laboratory of General Biochemistry and Physical Pharmacy to perform research on advanced optical microscopy methods for pharmaceutical applications. In 2004, he started his post-doctoral fellowship and was appointed Professor at Ghent University in 2008 where he is currently leading the Bio-Photonics Research Group in close collaboration with the Ghent Research Group on Nanomedicines. In 2015 he was awarded an ERC Consolidator Grant. His 
research focuses on the study of biological barriers of functional nanomaterials by advanced microscopy techniques and light-triggered drug delivery.

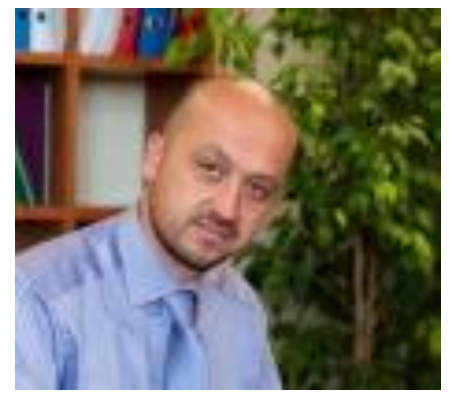

Stefaan C. De Smedt studied pharmacy and graduated from Ghent University in 1995 . He joined the pharmaceutical development group of Janssen Research Foundation (1995-97). Following post-doctoral research at the Departments of Pharmacy in Ghent and Utrecht he became Professor in Physical Pharmacy and Biopharmacy at Ghent University in 1999 where he founded the Ghent Research Group on Nanomedicines. He served as dean of his faculty from 2010-2014. Currently he is a Specially Appointed Professor of Nanjing Forestry University. In 2015, he became Editor of JCR for the region Europe-Middle East \& Africa. His research is situated at the interface between drug delivery, material sciences, physical chemistry and biophysics. 


\section{References}

[1] J.D. Sipe, M.D. Benson, J.N. Buxbaum, S.-I. Ikeda, G. Merlini, M.J.M. Saraiva, P. Westermark, Amyloid fibril proteins and amyloidosis: chemical identification and clinical classification International Society of Amyloidosis 2016 Nomenclature Guidelines, Amyloid Int. J. Exp. Clin. Investig. Off. J. Int. Soc. Amyloidosis. 23 (2016) 209-213. doi:10.1080/13506129.2016.1257986.

[2] M.S. Hipp, S.-H. Park, F.U. Hartl, Proteostasis impairment in protein-misfolding and aggregation diseases, Trends Cell Biol. 24 (2014) 506-514. doi:10.1016/j.tcb.2014.05.003.

[3] A.M. Blokhuis, E.J.N. Groen, M. Koppers, L.H. van den Berg, R.J. Pasterkamp, Protein aggregation in amyotrophic lateral sclerosis, Acta Neuropathol. (Berl.). 125 (2013) 777794. doi:10.1007/s00401-013-1125-6.

[4] K.L. Moreau, J.A. King, Protein misfolding and aggregation in cataract disease and prospects for prevention, Trends Mol. Med. 18 (2012) 273-282. doi:10.1016/j.molmed.2012.03.005.

[5] S. Meehan, Y. Berry, B. Luisi, C.M. Dobson, J.A. Carver, C.E. MacPhee, Amyloid Fibril Formation by Lens Crystallin Proteins and Its Implications for Cataract Formation, J. Biol. Chem. 279 (2004) 3413-3419. doi:10.1074/jbc.M308203200.

[6] M.F.B.G. Gebbink, B. Bouma, C. Maas, B.N. Bouma, Physiological responses to protein aggregates: Fibrinolysis, coagulation and inflammation (new roles for old factors), FEBS Lett. 583 (2009) 2691-2699. doi:10.1016/j.febslet.2009.06.013.

[7] R. Milston, M.C. Madigan, J. Sebag, Vitreous floaters: Etiology, diagnostics, and management, Surv. Ophthalmol. 61 (2016) 211-227. doi:10.1016/j.survophthal.2015.11.008.

[8] O.W. Moe, Kidney stones: pathophysiology and medical management, The Lancet. 367 (2006) 333-344. doi:10.1016/S0140-6736(06)68071-9.

[9] I. Brigger, C. Dubernet, P. Couvreur, Nanoparticles in cancer therapy and diagnosis, Adv. Drug Deliv. Rev. 64 (2012) 24-36. doi:10.1016/j.addr.2012.09.006.

[10] S.S. Kelkar, T.M. Reineke, Theranostics: Combining Imaging and Therapy, Bioconjug. Chem. 22 (2011) 1879-1903. doi:10.1021/bc200151q.

[11] P. Arosio, T.P. J. Knowles, S. Linse, On the lag phase in amyloid fibril formation, Phys. Chem. Chem. Phys. 17 (2015) 7606-7618. doi:10.1039/C4CP05563B.

[12] M. Novo, S. Freire, W. Al-Soufi, Critical aggregation concentration for the formation of early Amyloid- $\beta$ (1-42) oligomers, Sci. Rep. 8 (2018). doi:10.1038/s41598-018-199613.

[13] H. LeVine, Thioflavine T interaction with synthetic Alzheimer's disease beta-amyloid peptides: detection of amyloid aggregation in solution., Protein Sci. Publ. Protein Soc. 2 (1993) 404-410. 
[14] S.L. Gras, L.J. Waddington, K.N. Goldie, Transmission electron microscopy of amyloid fibrils, Methods Mol. Biol. Clifton NJ. 752 (2011) 197-214. doi:10.1007/978-1-60327223-0_13.

[15] C. Goldsbury, J. Kistler, U. Aebi, T. Arvinte, G.J.S. Cooper, Watching amyloid fibrils grow by time-lapse atomic force microscopy11Edited by W. Baumeister, J. Mol. Biol. 285 (1999) 33-39. doi:10.1006/jmbi.1998.2299.

[16] C.J. Barrow, A. Yasuda, P.T.M. Kenny, M.G. Zagorski, Solution conformations and aggregational properties of synthetic amyloid $\beta$-peptides of Alzheimer's disease: Analysis of circular dichroism spectra, J. Mol. Biol. 225 (1992) 1075-1093. doi:10.1016/0022-2836(92)90106-T.

[17] S.B. Malinchik, H. Inouye, K.E. Szumowski, D.A. Kirschner, Structural Analysis of Alzheimer's $\beta(1-40)$ Amyloid: Protofilament Assembly of Tubular Fibrils, Biophys. J. 74 (1998) 537-545. doi:10.1016/S0006-3495(98)77812-9.

[18] M. Zaman, E. Ahmad, A. Qadeer, G. Rabbani, R.H. Khan, Nanoparticles in relation to peptide and protein aggregation, Int. J. Nanomedicine. 9 (2014) 899-912. doi:10.2147/IJN.S54171.

[19] N.K. Ramesh, S. Sudhakar, E. Mani, Modeling of the Inhibitory Effect of Nanoparticles on Amyloid $\beta$ Fibrillation, Langmuir. 34 (2018) 4004-4012. doi:10.1021/acs.langmuir.8b00388.

[20] J.D. Harper, P.T. Lansbury, Models of amyloid seeding in Alzheimer's disease and scrapie: mechanistic truths and physiological consequences of the time-dependent solubility of amyloid proteins, Annu. Rev. Biochem. 66 (1997) 385-407. doi:10.1146/annurev.biochem.66.1.385.

[21] L. Fei, S. Perrett, Effect of Nanoparticles on Protein Folding and Fibrillogenesis, Int. J. Mol. Sci. 10 (2009) 646-655. doi:10.3390/ijms10020646.

[22] C. Cabaleiro-Lago, F. Quinlan-Pluck, I. Lynch, S. Lindman, A.M. Minogue, E. Thulin, D.M. Walsh, K.A. Dawson, S. Linse, Inhibition of Amyloid $\beta$ Protein Fibrillation by Polymeric Nanoparticles, J. Am. Chem. Soc. 130 (2008) 15437-15443. doi:10.1021/ja8041806.

[23] C. Cabaleiro-Lago, F. Quinlan-Pluck, I. Lynch, K.A. Dawson, S. Linse, Dual Effect of Amino Modified Polystyrene Nanoparticles on Amyloid $\beta$ Protein Fibrillation, ACS Chem. Neurosci. 1 (2010) 279-287. doi:10.1021/cn900027u.

[24] M. Mahmoudi, M.P. Monopoli, M. Rezaei, I. Lynch, F. Bertoli, J.J. McManus, K.A Dawson, The Protein Corona Mediates the Impact of Nanomaterials and Slows Amyloid Beta Fibrillation, ChemBioChem. 14 (2013) 568-572. doi:10.1002/cbic.201300007.

[25] T. Cedervall, I. Lynch, S. Lindman, T. Berggård, E. Thulin, H. Nilsson, K.A. Dawson, S. Linse, Understanding the nanoparticle-protein corona using methods to quantify exchange rates and affinities of proteins for nanoparticles, Proc. Natl. Acad. Sci. 104 (2007) 2050-2055. doi:10.1073/pnas.0608582104. 
[26] M. Lundqvist, J. Stigler, G. Elia, I. Lynch, T. Cedervall, K.A. Dawson, Nanoparticle size and surface properties determine the protein corona with possible implications for biological impacts, Proc. Natl. Acad. Sci. 105 (2008) 14265-14270. doi:10.1073/pnas.0805135105.

[27] D.M. Walsh, I. Klyubin, J.V. Fadeeva, M.J. Rowan, D.J. Selkoe, Amyloid- $\beta$ oligomers: their production, toxicity and therapeutic inhibition, Biochem. Soc. Trans. 30 (2002) 552-557. doi:10.1042/bst0300552.

[28] K. Shezad, K. Zhang, M. Hussain, H. Dong, C. He, X. Gong, X. Xie, J. Zhu, L. Shen, Surface Roughness Modulates Diffusion and Fibrillation of Amyloid- $\beta$ Peptide, Langmuir. 32 (2016) 8238-8244. doi:10.1021/acs.langmuir.6b01756.

[29] L. Xiao, D. Zhao, W.-H. Chan, M.M.F. Choi, H.-W. Li, Inhibition of beta 1-40 amyloid fibrillation with N-acetyl-1-cysteine capped quantum dots, Biomaterials. 31 (2010) 9198. doi:10.1016/j.biomaterials.2009.09.014.

[30] Y. Liu, L.-P. Xu, W. Dai, H. Dong, Y. Wen, X. Zhang, Graphene quantum dots for the inhibition of $\beta$ amyloid aggregation, Nanoscale. 7 (2015) 19060-19065. doi:10.1039/c5nr06282a.

[31] Q. Li, L. Liu, S. Zhang, M. Xu, X. Wang, C. Wang, F. Besenbacher, M. Dong, Modulating Aß33-42 Peptide Assembly by Graphene Oxide, Chem. - Eur. J. 20 (2014) 7236-7240. doi:10.1002/chem.201402022.

[32] M. Mahmoudi, O. Akhavan, M. Ghavami, F. Rezaee, S.M.A. Ghiasi, Graphene oxide strongly inhibits amyloid beta fibrillation, Nanoscale. 4 (2012) 7322-7325. doi:10.1039/C2NR31657A.

[33] F. Sauvage, S. Messaoudi, E. Fattal, G. Barratt, J. Vergnaud-Gauduchon, Heat shock proteins and cancer: How can nanomedicine be harnessed?, J. Controlled Release. 248 (2017) 133-143. doi:10.1016/j.jconrel.2017.01.013.

[34] P.J. Muchowski, J.L. Wacker, Modulation of neurodegeneration by molecular chaperones, Nat. Rev. Neurosci. 6 (2005) 11-22. doi:10.1038/nrn1587.

[35] A.B. Meriin, M.Y. Sherman, Role of molecular chaperones in neurodegenerative disorders, Int. J. Hyperth. Off. J. Eur. Soc. Hyperthermic Oncol. North Am. Hyperth. Group. 21 (2005) 403-419. doi:10.1080/02656730500041871.

[36] F. Huang, J. Wang, A. Qu, L. Shen, J. Liu, J. Liu, Z. Zhang, Y. An, L. Shi, Maintenance of amyloid $\beta$ peptide homeostasis by artificial chaperones based on mixed-shell polymeric micelles, Angew. Chem. Int. Ed Engl. 53 (2014) 8985-8990. doi:10.1002/anie.201400735.

[37] M. Garcia-Alloza, L.A. Borrelli, A. Rozkalne, B.T. Hyman, B.J. Bacskai, Curcumin labels amyloid pathology in vivo, disrupts existing plaques, and partially restores distorted neurites in an Alzheimer mouse model, J. Neurochem. 102 (2007) 1095-1104. doi:10.1111/j.1471-4159.2007.04613.x. 
[38] S. Palmal, A.R. Maity, B.K. Singh, S. Basu, N.R. Jana, N.R. Jana, Inhibition of Amyloid Fibril Growth and Dissolution of Amyloid Fibrils by Curcumin-Gold Nanoparticles, Chem. - Eur. J. 20 (2014) 6184-6191. doi:10.1002/chem.201400079.

[39] Y. Nomura, Y. Sasaki, M. Takagi, T. Narita, Y. Aoyama, K. Akiyoshi, Thermoresponsive controlled association of protein with a dynamic nanogel of hydrophobized polysaccharide and cyclodextrin: heat shock protein-like activity of artificial molecular chaperone, Biomacromolecules. 6 (2005) 447-452. doi:10.1021/bm049501t.

[40] Ikeda Keisuke, Okada Takuma, Sawada Shin-ichi, Akiyoshi Kazunari, Matsuzaki Katsumi, Inhibition of the formation of amyloid $\beta$-protein fibrils using biocompatible nanogels as artificial chaperones, FEBS Lett. 580 (2006) 6587-6595. doi:10.1016/j.febslet.2006.11.009.

[41] L.C. Preiss, L. Werber, V. Fischer, S. Hanif, K. Landfester, Y. Mastai, R. Muñoz-Espí, Amino-Acid-Based Chiral Nanoparticles for Enantioselective Crystallization, Adv. Mater. 27 (2015) 2728-2732. doi:10.1002/adma.201405531.

[42] C.A. De Carufel, N. Quittot, P.T. Nguyen, S. Bourgault, Delineating the Role of Helica Intermediates in Natively Unfolded Polypeptide Amyloid Assembly and Cytotoxicity, Angew. Chem. Int. Ed. 54 (2015) 14383-14387. doi:10.1002/anie.201507092.

[43] M. Li, S.E. Howson, K. Dong, N. Gao, J. Ren, P. Scott, X. Qu, Chiral Metallohelical Complexes Enantioselectively Target Amyloid $\beta$ for Treating Alzheimer's Disease, J. Am. Chem. Soc. 136 (2014) 11655-11663. doi:10.1021/ja502789e.

[44] D. Sun, W. Zhang, Q. Yu, X. Chen, M. Xu, Y. Zhou, J. Liu, Chiral penicillaminemodified selenium nanoparticles enantioselectively inhibit metal-induced amyloid $\beta$ aggregation for treating Alzheimer's disease, J. Colloid Interface Sci. 505 (2017) 10011010. doi:10.1016/j.jcis.2017.06.083.

[45] R. Malishev, E. Arad, S.K. Bhunia, S. Shaham-Niv, S. Kolusheva, E. Gazit, R. Jelinek, Chiral modulation of amyloid beta fibrillation and cytotoxicity by enantiomeric carbon dots, Chem. Commun. 54 (2018) 7762-7765. doi:10.1039/C8CC03235A.

[46] S. Mourtas, A.N. Lazar, E. Markoutsa, C. Duyckaerts, S.G. Antimisiaris, Multifunctional nanoliposomes with curcumin-lipid derivative and brain targeting functionality with potential applications for Alzheimer disease, Eur. J. Med. Chem. 80 (2014) 175-183. doi:10.1016/j.ejmech.2014.04.050.

[47] L. Bana, S. Minniti, E. Salvati, S. Sesana, V. Zambelli, A. Cagnotto, A. Orlando, E. Cazzaniga, R. Zwart, W. Scheper, M. Masserini, F. Re, Liposomes bi-functionalized with phosphatidic acid and an ApoE-derived peptide affect $A \beta$ aggregation features and cross the blood-brain-barrier: implications for therapy of Alzheimer disease, Nanomedicine Nanotechnol. Biol. Med. 10 (2014) 1583-1590. doi:10.1016/j.nano.2013.12.001.

[48] E. Abbasi, S.F. Aval, A. Akbarzadeh, M. Milani, H.T. Nasrabadi, S.W. Joo, Y. Hanifehpour, K. Nejati-Koshki, R. Pashaei-Asl, Dendrimers: synthesis, applications, and properties, Nanoscale Res. Lett. 9 (2014) 247. doi:10.1186/1556-276X-9-247. 
[49] A. Rekas, V. Lo, G.E. Gadd, R. Cappai, S.I. Yun, PAMAM dendrimers as potential agents against fibrillation of alpha-synuclein, a Parkinson's disease-related protein, Macromol. Biosci. 9 (2009) 230-238. doi:10.1002/mabi.200800242.

[50] K. Milowska, J. Grochowina, N. Katir, A. El Kadib, J.-P. Majoral, M. Bryszewska, T Gabryelak, Viologen-Phosphorus Dendrimers Inhibit $\alpha$-Synuclein Fibrillation, Mol. Pharm. 10 (2013) 1131-1137. doi:10.1021/mp300636h.

[51] K. Milowska, T. Gabryelak, M. Bryszewska, A.-M. Caminade, J.-P. Majoral, Phosphorus-containing dendrimers against $\alpha$-synuclein fibril formation, Int. J. Biol. Macromol. 50 (2012) 1138-1143. doi:10.1016/j.ijbiomac.2012.02.003.

[52] K. Milowska, A. Szwed, M. Mutrynowska, R. Gomez-Ramirez, F.J. de la Mata, T. Gabryelak, M. Bryszewska, Carbosilane dendrimers inhibit $\alpha$-synuclein fibrillation and prevent cells from rotenone-induced damage, Int. J. Pharm. 484 (2015) 268-275. doi:10.1016/j.ijpharm.2015.02.066.

[53] K. Laumann, U. Boas, H.M. Larsen, P.M.H. Heegaard, A.-L. Bergström, Urea and Thiourea Modified Polypropyleneimine Dendrimers Clear Intracellular $\alpha$-Synuclein Aggregates in a Human Cell Line, Biomacromolecules. 16 (2015) 116-124. doi:10.1021/bm501244m.

[54] B. Ahmad, L.J. Lapidus, Curcumin Prevents Aggregation in $\alpha$-Synuclein by Increasing Reconfiguration Rate, J. Biol. Chem. 287 (2012) 9193-9199. doi:10.1074/jbc.M111.325548.

[55] N. Taebnia, D. Morshedi, S. Yaghmaei, F. Aliakbari, F. Rahimi, A. Arpanaei, Curcumin-Loaded Amine-Functionalized Mesoporous Silica Nanoparticles Inhibit $\alpha$ Synuclein Fibrillation and Reduce Its Cytotoxicity-Associated Effects, Langmuir. 32 (2016) 13394-13402. doi:10.1021/acs.langmuir.6b02935.

[56] D. Kim, J.M. Yoo, H. Hwang, J. Lee, S.H. Lee, S.P. Yun, M.J. Park, M. Lee, S. Choi, S.H. Kwon, S. Lee, S.-H. Kwon, S. Kim, Y.J. Park, M. Kinoshita, Y.-H. Lee, S. Shin, S.R. Paik, S.J. Lee, S. Lee, B.H. Hong, H.S. Ko, Graphene quantum dots prevent $\alpha-$ synucleinopathy in Parkinson's disease, Nat. Nanotechnol. (2018) 1. doi:10.1038/s41565-018-0179-y.

[57] T. Arakawa, D. Ejima, Y. Kita, K. Tsumoto, Small molecule pharmacological chaperones: From thermodynamic stabilization to pharmaceutical drugs, Biochim. Biophys. Acta. 1764 (2006) 1677-1687. doi:10.1016/j.bbapap.2006.08.012.

[58] M. Tanaka, Y. Machida, S. Niu, T. Ikeda, N.R. Jana, H. Doi, M. Kurosawa, M. Nekooki, N. Nukina, Trehalose alleviates polyglutamine-mediated pathology in a mouse model of Huntington disease, Nat. Med. 10 (2004) 148-154. doi:10.1038/nm985.

[59] N. Pradhan, S. Shekhar, N.R. Jana, N.R. Jana, Sugar-Terminated Nanoparticle Chaperones Are 102-105 Times Better Than Molecular Sugars in Inhibiting Protein Aggregation and Reducing Amyloidogenic Cytotoxicity, ACS Appl. Mater. Interfaces. 9 (2017) 10554-10566. doi:10.1021/acsami.7b01886.

[60] K. Debnath, N. Pradhan, B.K. Singh, N.R. Jana, N.R. Jana, Poly(trehalose) Nanoparticles Prevent Amyloid Aggregation and Suppress Polyglutamine Aggregation 
in a Huntington's Disease Model Mouse, ACS Appl. Mater. Interfaces. 9 (2017) 2412624139. doi:10.1021/acsami.7b06510.

[61] N. Pradhan, N.R. Jana, N.R. Jana, Inhibition of Protein Aggregation by Iron Oxide Nanoparticles Conjugated with Glutamine- and Proline-Based Osmolytes, ACS Appl. Nano Mater. 1 (2018) 1094-1103. doi:10.1021/acsanm.7b00245.

[62] R. Liu, H. Barkhordarian, S. Emadi, C.B. Park, M.R. Sierks, Trehalose differentially inhibits aggregation and neurotoxicity of beta-amyloid 40 and 42, Neurobiol. Dis. 20 (2005) 74-81. doi:10.1016/j.nbd.2005.02.003.

[63] C.-H. Chen, T. Yao, Q. Zhang, Y.-M. He, L.-H. Xu, M. Zheng, G.-R. Zhou, Y. Zhang, H.-J. Yang, P. Zhou, Influence of trehalose on human islet amyloid polypeptide fibrillation and aggregation, RSC Adv. 6 (2016) 15240-15246. doi:10.1039/C5RA27689F.

[64] P. Westermark, A. Andersson, G.T. Westermark, Islet Amyloid Polypeptide, Islet Amyloid, and Diabetes Mellitus, Physiol. Rev. 91 (2011) 795-826. doi:10.1152/physrev.00042.2009.

[65] C. Cabaleiro-Lago, I. Lynch, K.A. Dawson, S. Linse, Inhibition of IAPP and IAPP(20-29) Fibrillation by Polymeric Nanoparticles, Langmuir. 26 (2010) 3453-3461. doi:10.1021/la902980d.

[66] E.N. Gurzov, B. Wang, E.H. Pilkington, P. Chen, A. Kakinen, W.J. Stanley, S.A. Litwak, E.G. Hanssen, T.P. Davis, F. Ding, P.C. Ke, Inhibition of hIAPP Amyloid Aggregation and Pancreatic $\beta$-Cell Toxicity by OH-Terminated PAMAM Dendrimer, Small. 12 (2016) 1615-1626. doi:10.1002/smll.201502317.

[67] F.E. Dische, C. Wernstedt, G.T. Westermark, P. Westermark, M.B. Pepys, J.A. Rennie, S.G. Gilbey, P.J. Watkins, Insulin as an amyloid-fibril protein at sites of repeated insulin injections in a diabetic patient, Diabetologia. 31 (1988) 158-161. doi:10.1007/BF00276849.

[68] N. Tanio, T. Nozaki, M. Matsusako, J. Starkey, K. Suzuki, Imaging characteristics of subcutaneous amyloid deposits in diabetic patients: the "insulin ball," Skeletal Radiol. 47 (2018) 85-92. doi:10.1007/s00256-017-2749-8.

[69] S. Li, L. Wang, C.C. Chusuei, V.M. Suarez, P.L. Blackwelder, M. Micic, J. Orbulescu, R.M. Leblanc, Nontoxic Carbon Dots Potently Inhibit Human Insulin Fibrillation, Chem. Mater. 27 (2015) 1764-1771. doi:10.1021/cm504572b.

[70] Y. Ma, R. Huang, W. Qi, R. Su, Z. He, Fluorescent silicon nanoparticles inhibit the amyloid fibrillation of insulin, J. Mater. Chem. B. 7 (2019) 1397-1403. doi:10.1039/C8TB02964D.

[71] K. Siposova, K. Pospiskova, Z. Bednarikova, I. Safarik, M. Safarikova, M. Kubovcikova, P. Kopcansky, Z. Gazova, The molecular mass of dextran used to modify magnetite nanoparticles affects insulin amyloid aggregation, J. Magn. Magn. Mater. 427 (2017) 48-53. doi:10.1016/j.jmmm.2016.10.083. 
[72] E.H. Pilkington, M. Lai, X. Ge, W.J. Stanley, B. Wang, M. Wang, A. Kakinen, M.-A. Sani, M.R. Whittaker, E.N. Gurzov, F. Ding, J.F. Quinn, T.P. Davis, P.C. Ke, Star Polymers Reduce Islet Amyloid Polypeptide Toxicity via Accelerated Amyloid Aggregation, Biomacromolecules. 18 (2017) 4249-4260. doi:10.1021/acs.biomac.7b01301.

[73] H.J. Chung, A. Steplewski, K.Y. Chung, J. Uitto, A. Fertala, Collagen Fibril Formation, J. Biol. Chem. 283 (2008) 25879-25886. doi:10.1074/jbc.M804272200.

[74] A. Steplewski, A. Fertala, Inhibition of collagen fibril formation, Fibrogenesis Tissue Repair. 5 (2012) S29. doi:10.1186/1755-1536-5-S1-S29.

[75] B.G. Anand, K. Dubey, D.S. Shekhawat, K.P. Prajapati, K. Kar, Strategically Designed Antifibrotic Gold Nanoparticles to Prevent Collagen Fibril Formation, Langmuir. 33 (2017) 13252-13261. doi:10.1021/acs.langmuir.7b01504.

[76] C.G. Wilson, P.N. Sisco, F.A. Gadala-Maria, C.J. Murphy, E.C. Goldsmith, Polyelectrolyte-coated gold nanorods and their interactions with type I collagen, Biomaterials. 30 (2009) 5639-5648. doi:10.1016/j.biomaterials.2009.07.011.

[77] C. Cabaleiro-Lago, O. Szczepankiewicz, S. Linse, The Effect of Nanoparticles on Amyloid Aggregation Depends on the Protein Stability and Intrinsic Aggregation Rate, Langmuir. 28 (2012) 1852-1857. doi:10.1021/la203078w.

[78] K. Dubey, B.G. Anand, R. Badhwar, G. Bagler, P.N. Navya, H.K. Daima, K. Kar, Tyrosine- and tryptophan-coated gold nanoparticles inhibit amyloid aggregation of insulin, Amino Acids. 47 (2015) 2551-2560. doi:10.1007/s00726-015-2046-6.

[79] Y. Matsuoka, M. Saito, J. LaFrancois, M. Saito, K. Gaynor, V. Olm, L. Wang, E. Casey, Y. Lu, C. Shiratori, C. Lemere, K. Duff, Novel therapeutic approach for the treatment of Alzheimer's disease by peripheral administration of agents with an affinity to betaamyloid, J. Neurosci. Off. J. Soc. Neurosci. 23 (2003) 29-33.

[80] R.B. DeMattos, K.R. Bales, D.J. Cummins, J.-C. Dodart, S.M. Paul, D.M. Holtzman, Peripheral anti-A $\beta$ antibody alters CNS and plasma $A \beta$ clearance and decreases brain $A \beta$ burden in a mouse model of Alzheimer's disease, Proc. Natl. Acad. Sci. U. S. A. 98 (2001) 8850-8855. doi:10.1073/pnas.151261398.

[81] R.B. DeMattos, K.R. Bales, D.J. Cummins, S.M. Paul, D.M. Holtzman, Brain to plasma amyloid-beta efflux: a measure of brain amyloid burden in a mouse model of Alzheimer's disease, Science. 295 (2002) 2264-2267. doi:10.1126/science.1067568.

[82] J. Nicolas, P. Couvreur, Synthesis of poly(alkyl cyanoacrylate)-based colloidal nanomedicines, Wiley Interdiscip. Rev. Nanomed. Nanobiotechnol. 1 (2009) 111-127. doi:10.1002/wnan.15.

[83] D. Carradori, C. Balducci, F. Re, D. Brambilla, B. Le Droumaguet, O. Flores, A Gaudin, S. Mura, G. Forloni, L. Ordoñez-Gutierrez, F. Wandosell, M. Masserini, P. Couvreur, J. Nicolas, K. Andrieux, Antibody-functionalized polymer nanoparticle leading to memory recovery in Alzheimer's disease-like transgenic mouse model, Nanomedicine Nanotechnol. Biol. Med. 14 (2018) 609-618. doi:10.1016/j.nano.2017.12.006. 
[84] S. Mancini, S. Minniti, M. Gregori, G. Sancini, A. Cagnotto, P.-O. Couraud, L. Ordóñez-Gutiérrez, F. Wandosell, M. Salmona, F. Re, The hunt for brain A $\beta$ oligomers by peripherally circulating multi-functional nanoparticles: Potential therapeutic approach for Alzheimer disease, Nanomedicine Nanotechnol. Biol. Med. 12 (2016) 43-52. doi:10.1016/j.nano.2015.09.003.

[85] Q. Song, M. Huang, L. Yao, X. Wang, X. Gu, J. Chen, J. Chen, J. Huang, Q. Hu, T. Kang, Z. Rong, H. Qi, G. Zheng, H. Chen, X. Gao, Lipoprotein-Based Nanoparticles Rescue the Memory Loss of Mice with Alzheimer's Disease by Accelerating the Clearance of Amyloid-Beta, ACS Nano. 8 (2014) 2345-2359. doi:10.1021/nn4058215.

[86] Q. Luo, Y.-X. Lin, P.-P. Yang, Y. Wang, G.-B. Qi, Z.-Y. Qiao, B.-N. Li, K. Zhang, J.-P. Zhang, L. Wang, H. Wang, A self-destructive nanosweeper that captures and clears amyloid $\beta$-peptides, Nat. Commun. 9 (2018) 1802. doi:10.1038/s41467-018-04255-Z.

[87] G. Bort, S. Catoen, H. Borderies, A. Kebsi, S. Ballet, G. Louin, M. Port, C. Ferroud, Gadolinium-based contrast agents targeted to amyloid aggregates for the early diagnosis of Alzheimer's disease by MRI, Eur. J. Med. Chem. 87 (2014) 843-861. doi:10.1016/j.ejmech.2014.10.016.

[88] C.-C. Yang, S.-Y. Yang, J.-J. Chieh, H.-E. Horng, C.-Y. Hong, H.-C. Yang, K.H. Chen, B.Y. Shih, T.-F. Chen, M.-J. Chiu, Biofunctionalized Magnetic Nanoparticles for Specifically Detecting Biomarkers of Alzheimer's Disease in Vitro, ACS Chem. Neurosci. 2 (2011) 500-505. doi:10.1021/cn200028j.

[89] H. Skaat, S. Margel, Synthesis of fluorescent-maghemite nanoparticles as multimodal imaging agents for amyloid- $\beta$ fibrils detection and removal by a magnetic field, Biochem. Biophys. Res. Commun. 386 (2009) 645-649. doi:10.1016/j.bbrc.2009.06.110.

[90] F.H. Ghahremani, A. Sazgarnia, M.H. Bahreyni-Toosi, O. Rajabi, A. Aledavood, Efficacy of microwave hyperthermia and chemotherapy in the presence of gold nanoparticles: an in vitro study on osteosarcoma, Int. J. Hyperth. Off. J. Eur. Soc. Hyperthermic Oncol. North Am. Hyperth. Group. 27 (2011) 625-636. doi:10.3109/02656736.2011.587363.

[91] N.G. Bastus, M.J. Kogan, R. Amigo, D. Grillo-Bosch, E. Araya, A. Turiel, A. Labarta, E. Giralt, V.F. Puntes, Gold nanoparticles for selective and remote heating of $\beta$-amyloid protein aggregates, Mater. Sci. Eng. C. 27 (2007) 1236-1240. doi:10.1016/j.msec.2006.08.003.

[92] E. Araya, I. Olmedo, N.G. Bastus, S. Guerrero, V.F. Puntes, E. Giralt, M.J. Kogan, Gold Nanoparticles and Microwave Irradiation Inhibit Beta-Amyloid Amyloidogenesis, Nanoscale Res. Lett. 3 (2008) 435-443. doi:10.1007/s11671-008-9178-5.

[93] N.V.S. Vallabani, S. Singh, Recent advances and future prospects of iron oxide nanoparticles in biomedicine and diagnostics, 3 Biotech. 8 (2018). doi:10.1007/s13205018-1286-z. 
[94] S. Laurent, S. Dutz, U.O. Häfeli, M. Mahmoudi, Magnetic fluid hyperthermia: Focus on superparamagnetic iron oxide nanoparticles, Adv. Colloid Interface Sci. 166 (2011) 823. doi:10.1016/j.cis.2011.04.003.

[95] M.G. Lansberg, V.N. Thijs, R. Bammer, S. Kemp, C.A.C. Wijman, M.P. Marks, G.W. Albers, DEFUSE Investigators, Risk factors of symptomatic intracerebral hemorrhage after tPA therapy for acute stroke, Stroke. 38 (2007) 2275-2278. doi:10.1161/STROKEAHA.106.480475.

[96] E. Voros, M. Cho, M. Ramirez, A.L. Palange, E.D. Rosa, J. Key, Z. Garami, A.B. Lumsden, P. Decuzzi, TPA Immobilization on Iron Oxide Nanocubes and Localized Magnetic Hyperthermia Accelerate Blood Clot Lysis, Adv. Funct. Mater. 25 (2015) 1709-1718. doi:10.1002/adfm.201404354.

[97] A.T. Brown, R. Flores, E. Hamilton, P.K. Roberson, M.J. Borrelli, W.C. Culp, Microbubbles Improve Sonothrombolysis In Vitro and Decrease Hemorrhage In Vivo in a Rabbit Stroke Model, Invest. Radiol. 46 (2011). doi:10.1097/RLI.0b013e318200757a.

[98] M. Li, X. Yang, J. Ren, K. Qu, X. Qu, Using Graphene Oxide High Near-Infrared Absorbance for Photothermal Treatment of Alzheimer's Disease, Adv. Mater. 24 (2012) 1722-1728. doi:10.1002/adma.201104864.

[99] S. Sudhakar, P.B. Santhosh, E. Mani, Dual Role of Gold Nanorods: Inhibition and Dissolution of A $\beta$ Fibrils Induced by Near IR Laser, ACS Chem. Neurosci. 8 (2017) 2325-2334. doi:10.1021/acschemneuro.7b00238.

[100] R.C. Triulzi, Q. Dai, J. Zou, R.M. Leblanc, Q. Gu, J. Orbulescu, Q. Huo, Photothermal ablation of amyloid aggregates by gold nanoparticles, Colloids Surf. B Biointerfaces. 63 (2008) 200-208. doi:10.1016/j.colsurfb.2007.12.006.

[101] X. Huang, P.K. Jain, I.H. El-Sayed, M.A. El-Sayed, Plasmonic photothermal therapy (PPTT) using gold nanoparticles, Lasers Med. Sci. 23 (2008) 217. doi:10.1007/s10103007-0470-x.

[102] R. Xiong, K. Raemdonck, K. Peynshaert, I. Lentacker, I. De Cock, J. Demeester, S.C De Smedt, A.G. Skirtach, K. Braeckmans, Comparison of Gold Nanoparticle Mediated Photoporation: Vapor Nanobubbles Outperform Direct Heating for Delivering Macromolecules in Live Cells, ACS Nano. 8 (2014) 6288-6296. doi:10.1021/nn5017742.

[103] D. Lin, R. He, S. Li, Y. Xu, J. Wang, G. Wei, M. Ji, X. Yang, Highly Efficient Destruction of Amyloid- $\beta$ Fibrils by Femtosecond Laser-Induced Nanoexplosion of Gold Nanorods, ACS Chem. Neurosci. 7 (2016) 1728-1736. doi:10.1021/acschemneuro.6b00244.

[104] P. Kang, Z. Chen, S.O. Nielsen, K. Hoyt, S. D’Arcy, J.J. Gassensmith, Z. Qin, Molecular Hyperthermia: Spatiotemporal Protein Unfolding and Inactivation by Nanosecond Plasmonic Heating, Small Weinh. Bergstr. Ger. 13 (2017). doi:10.1002/smll.201700841.

[105] F. Sauvage, J.C. Fraire, K. Remaut, J. Sebag, K. Peynshaert, M. Harrington, F.J. Van de velde, R. Xiong, M.-J. Tassignon, T. Brans, K. Braeckmans, S.C. De Smedt, Photo- 
Ablation of Human Vitreous Opacities by Light-Induced Vapor Nanobubbles, ACS Nano. (2019). doi:10.1021/acsnano.9b04050.

[106] P.N. Bishop, D.F. Holmes, K.E. Kadler, D. McLeod, K.J. Bos, Age-Related Changes on the Surface of Vitreous Collagen Fibrils, Invest. Ophthalmol. Vis. Sci. 45 (2004) 1041-1046. doi:10.1167/iovs.03-1017.

[107] P.N. Bishop, Structural macromolecules and supramolecular organisation of the vitreous gel, Prog. Retin. Eye Res. 19 (2000) 323-344.

[108] S.J. Soenen, P. Rivera-Gil, J.-M. Montenegro, W.J. Parak, S.C. De Smedt, K. Braeckmans, Cellular toxicity of inorganic nanoparticles: Common aspects and guidelines for improved nanotoxicity evaluation, Nano Today. 6 (2011) 446-465. doi:10.1016/j.nantod.2011.08.001.

[109] P. Rivera Gil, D. Hühn, L.L. del Mercato, D. Sasse, W.J. Parak, Nanopharmacy: Inorganic nanoscale devices as vectors and active compounds, Pharmacol. Res. 62 (2010) 115-125. doi:10.1016/j.phrs.2010.01.009.

[110] A.R. Ziefuß, S. Reichenberger, C. Rehbock, I. Chakraborty, M. Gharib, W.J. Parak, S. Barcikowski, Laser Fragmentation of Colloidal Gold Nanoparticles with High-Intensity Nanosecond Pulses is Driven by a Single-Step Fragmentation Mechanism with a Defined Educt Particle-Size Threshold, J. Phys. Chem. C. 122 (2018) 22125-22136. doi:10.1021/acs.jpcc.8b04374.

[111] A.C. Anselmo, S. Mitragotri, A Review of Clinical Translation of Inorganic Nanoparticles, AAPS J. 17 (2015) 1041-1054. doi:10.1208/s12248-015-9780-2.

[112] P.C. Naha, K. Bhattacharya, T. Tenuta, K.A. Dawson, I. Lynch, A. Gracia, F.M. Lyng, H.J. Byrne, Intracellular localisation, geno- and cytotoxic response of polyNisopropylacrylamide (PNIPAM) nanoparticles to human keratinocyte (HaCaT) and colon cells (SW 480), Toxicol. Lett. 198 (2010) 134-143. doi:10.1016/j.toxlet.2010.06.011.

[113] M.A. Cooperstein, H.E. Canavan, Assessment of cytotoxicity of (N-isopropyl acrylamide) and Poly(N-isopropyl acrylamide)-coated surfaces, Biointerphases. 8 (2013) 19. doi:10.1186/1559-4106-8-19.

[114] L.H. Lima, Y. Morales, T. Cabral, Ocular Biocompatibility of Poly-NIsopropylacrylamide (pNIPAM), J. Ophthalmol. (2016). doi:10.1155/2016/5356371.

[115] A. Albanese, P.S. Tang, W.C.W. Chan, The Effect of Nanoparticle Size, Shape, and Surface Chemistry on Biological Systems, Annu. Rev. Biomed. Eng. 14 (2012) 1-16. doi:10.1146/annurev-bioeng-071811-150124.

[116] Y. Porat, A. Abramowitz, E. Gazit, Inhibition of Amyloid Fibril Formation by Polyphenols: Structural Similarity and Aromatic Interactions as a Common Inhibition Mechanism, Chem. Biol. Drug Des. 67 (2006) 27-37. doi:10.1111/j.17470285.2005.00318.x.

[117] G. Forloni, L. Colombo, L. Girola, F. Tagliavini, M. Salmona, Anti-amyloidogenic activity of tetracyclines: studies in vitro, FEBS Lett. 487 (2001) 404-407. doi:10.1016/S0014-5793(00)02380-2. 
[118] J. McLaurin, R. Cecal, M.E. Kierstead, X. Tian, A.L. Phinney, M. Manea, J.E. French, M.H.L. Lambermon, A.A. Darabie, M.E. Brown, C. Janus, M.A. Chishti, P. Horne, D. Westaway, P.E. Fraser, H.T.J. Mount, M. Przybylski, P.S. George-Hyslop,

Therapeutically effective antibodies against amyloid- $\beta$ peptide target amyloid- $\beta$ residues 4-10 and inhibit cytotoxicity and fibrillogenesis, Nat. Med. 8 (2002) 1263-1269. doi: $10.1038 / \mathrm{nm} 790$.

[119] M. Fändrich, Oligomeric Intermediates in Amyloid Formation: Structure Determination and Mechanisms of Toxicity, J. Mol. Biol. 421 (2012) 427-440. doi:10.1016/j.jmb.2012.01.006.

[120] C.G. Glabe, Common mechanisms of amyloid oligomer pathogenesis in degenerative disease, Neurobiol. Aging. 27 (2006) 570-575. doi:10.1016/j.neurobiolaging.2005.04.017. 